\title{
FIDEL GATELL MORAGAS, DE TORREDEMBARRA A PUERTO RICO
}

\author{
Josep Fàbregas Roig* \\ Universitat Rovira i Virgili \\ jose.fabregas@urv.cat
}

RESUMEN: El presente artículo, a través de la figura de Fidel Gatell Moragas, pretende estudiar la trayectoria que pudieron seguir los emigrantes españoles que, a comienzos del siglo XIX, marcharon hacia América con la idea de encontrar una mejor manera de vivir o incluso hacer fortuna. Algunos de ellos lo consiguieron, convirtiéndose en importantes hacendados o comerciantes y regresaron, mientras que otros optaron por quedarse. El análisis de documentación epistolar-privaday de fuentes oficiales nos ha permitido seguir el rastro de este emigrante catalán, miembro de una familia notable, en su viaje hacia Puerto Rico.

Palabras clave: Emigración, comerciante, Puerto Rico, siglo XIX, aduana.

\section{FIDEL GATELL MORAGAS, FROM TORREDEMBARRA TO PUERTO RICO}

ABSTRACT: This article, through the figure of Fidel Gatell Moragas, is aimed at studying the trajectory that may have been followed by Spanish emigrants who, at the beginning of the $19^{\text {th }}$ Century went to America with the idea of finding a better way to live or even making a fortune. Some of them succeeded, becoming important landowners or merchants, and returned, while others chose to stay. The analysis of epistolary documentation -private- and official sources has allowed us to follow the trail of this Catalan emigrant, a member of a remarkable family, on his trip to Puerto Rico.

Keywords: Emigration, trader, Puerto Rico, 19th Century, customhouse.

Recibido: 10 de Mayo de 2017 Aceptado: 12 de Junio de 2017

* Colaborador del grupo de investigación: Centre d'Estudis sobre Conflictes Socials (CECOS) de la Universitat Rovira i Virgili. 


\section{Introducción}

El objetivo de este estudio es analizar la trayectoria de Fidel Gatell Moragas, vecino de Torredembarra, miembro de una familia acomodada que, en su primera juventud, decidió emprender la aventura americana. Al mismo tiempo nos introducimos en el conocimiento de la sociedad y la economía, a finales del siglo XVIII y comienzos del XIX, tanto de su localidad de procedencia como de Puerto Rico, lugar de destino.

Tal como sucedió en el resto de Cataluña, durante el siglo XVIII, Torredembarra tuvo un notable incremento demográfico. Finalizada la guerra de Sucesión, el censo de 1719 le asignaba 885 habitantes y en el de 1787 (censo de Floridablanca) había alcanzado 1.903. El de 1838, según datos del archivo municipal, nos ofrece un total de 1.525 habitantes, que ocupaban 326 casas; lo que suponía un retroceso con relación a los cómputos de finales del siglo XVIII. El diccionario de Madoz (1845) le adjudicaba unas 500 casas, 100 de las cuales estaban deshabitadas y en ruina, totalizando 1.860 habitantes'.

La proximidad de Torredembarra a Tarragona, plaza fuerte y capital del Corregimiento del mismo nombre, significó para la villa participar directa y activamente en los acontecimientos políticos y militares que se sucedieron. La demarcación de Torredembarra fue testimonio de los hechos que se produjeron como consecuencia de los conflictos de la época moderna: guerra dels Segadors en el siglo XVII, guerras de Sucesión y del Rosellón en el XVIII y guerra de la Independencia, a inicios del XIX.

Durante el siglo XVIII, la economía de Torredembarra se fundamentó en las actividades agrícolas, pesqueras y comerciales. Su ubicación en el litoral mediterráneo y el hecho de disponer de aduana le permitió acceder a los circuitos comerciales marítimos, por lo que serán numerosos los vínculos con el comercio colonial americano ${ }^{2}$.

Los datos proporcionados por Agustí Segarra, en relación a los derechos de entrada y salida de mercancías de las aduanas de la provincia marítima de Tarragona, nos permiten apreciar el progreso de Torredembarra entre 1730 y 1770 , coincidiendo con las posibilidades de exportación. A mediados de siglo, estos derechos, con respecto a las restantes localidades de dicha provincia, la situaban en segundo lugar, por detrás del puerto de Salou y por delante de los de Cambrils, Sitges y Vilanova. Ciertamente ocupaba una posición envidiable, donde vinos y aguardientes eran los productos de referencia ${ }^{3}$.

1. Anguera Nolla, P., Rovira Gómez, S. J., Història de Torredembarra. Segles XVIII i XIX. Ajuntament de Torredembarra, 1984, p. 75. Iglesias Fort, J., El Cens del comte de Floridablanca, 1787: part de Catalunya. Barcelona, Fundació Salvador Vives Casajuana, 1969-1970. Madoz, P., Diccionario geográfico-estadístico-histórico de España y sus posesiones de ultramar. Vol. 15, Madrid, Establecimiento tipográfico de P. Madoz y L. Sagasti, 1846-1850, p. 81.

2. Cardó Soler, J., L'Evolució dels conreus del Camp de Tarragona a partir del segle XVIII. Valls, Institut d'Estudis Vallencs, 1983.

3. Segarra Blasco, A., L'Economia de Reus al segle XVIII: el comerç de l'aiguardent. Reus, Centre de Lectura, 1988. También en Aiguardent i mercat a la Catalunya del segle XVIII. Vic, EUMO, 1994. 
Del mismo modo, los trabajos de Roberto Fernández y Carlos Martínez Shaw confirman que, durante el siglo XVIII, Torredembarra ocupó un lugar destacado dentro de la misma provincia marítima, tanto por lo que se refiere al número de marineros como al de embarcaciones de comercio ${ }^{4}$.

Durante la segunda mitad del siglo XVIII, gracias al Decreto e Instrucción de 16 de octubre de 1765 sobre el comercio libre y al conocido Reglamento y Aranceles Reales para el Comercio Libre de España a Indias de 12 de octubre de 1778, Cataluña pudo comerciar directamente, con pleno derecho, con las colonias americanas. Serán numerosos los patrones de Torredembarra que, dentro de esta coyuntura, participarán en la exportación de productos catalanes en dirección a América. El comercio de vino y de aguardiente era una actividad habitual de sus comerciantes ${ }^{5}$.

Tenemos algunos nombres que testimonian esta actividad. Pau Mascaró, el año 1783, se embarcó en la saetía Verge del Bon Viatge del capitán Desideri Comes, de la matrícula de Mataró. En 1785, Pere Mauri se asoció a Josep A. Flaquer, perteneciente al comercio de La Habana. En 1787, Francesc Comes viajó a América en la saetía Verge del Carme del capitán Pere Bis, de la matrícula de Sitges. Dos años más tarde Josep Ivern haría lo mismo en una embarcación del mismo nombre. En 1792, Adrià Lluch navegaba en la polacra Sant Antoni de Pàdua del patrón Isidre Pascual. En 1793, Pere Badia se había embarcado en la polacra Santiago de les Ànimes del capitán Francesc Bru, matriculada en Mataró. En 1795, Jordi Pedrol, por cuestión de negocios, también viajó a América; Jeroni Foguet, en 1792, se vio obligado a establecer una fianza para poder trasladarse a tierras americanas: el destino era Nueva Orleans y realizó el viaje en la polacra Mare de Déu del Roser, en el año 1794 se vio afectado por el naufragio de la saetía Sant Quirze i Santa Julita delante del litoral tortosino y en 1795 se desplazaba nuevamente hacia el continente americano. El comerciante Josep Antoni Flaquer Lluch, en el año 1797, residía en La Habana. En 1799, Joan Baptista Roig también se trasladó a América. Finalmente, cabe destacar la presencia de Esteve Gatell, capitán de la saetía Santa Rosalía, perteneciente a una importante familia vinculada a las actividades marítimas ${ }^{6}$.

Casi de forma simultánea, se había iniciado un proceso migratorio que tendrá continuidad a lo largo del siglo XIX. Entre 1778 y 1833, desde el Camp de Tarragona, se tramitaron 331 expedientes de emigrantes para viajar a América, de los cuales 121 correspondían a Torredembarra y a Clarà .

4. Fernández Díaz, R., Martínez Shaw, C., "La gente de mar en la Cataluña del XVIII", en Actes I Congrés d'Història Moderna de Catalunya, Barcelona, 1984, pp. 553-568.

5. Segarra Blasco, A., L'Economia de Reus al segle XVIII.

6. Anguera Nolla, P., Rovira Gómez, S. J., Història de Torredembarra, pp. 27-37. Rodrigo Alharilla, M., Indians a Catalunya, capitals cubans en l'economia catalana. Barcelona, Pagès, 2007, pp. 238-240.

7. Puente Pérez, G., Fàbregas Roig, J. "L'emigració a Llatinoamèrica (1778-1833): el cas de Torredembarra". Recull deTreballs, 15 (2014), pp. 11-49. Puente Pérez, G., L'emigració 


\section{La familia Moragas}

Los Moragas pertenecían a una estirpe de comerciantes y fabricantes de la localidad de Valls. Eran negociantes en el sentido más genuino del concepto; su actividad económica era muy amplia pues si existía la posibilidad de obtener algún beneficio no importaba el tipo de inversión a realizar. Desde dicha ciudad desplegaron una intensa actividad mercantil, situándose entre las élites económicas del Principado.

Eran al mismo tiempo propietarios rurales, fabricantes de tejidos de lana, seda y algodón, vendedores al por mayor y al por menor, destiladores de aguardiente, partícipes de diversas embarcaciones y administradores de la lotería del estado y del monopolio de la sal, entre otras actividades ${ }^{8}$.

El origen de la familia hay que buscarlo en Barcelona, en la figura de Francesc Moragas, nacido en 1615, ciutadà honrat de aquella ciudad, aunque fue su hijo Francesc Moragas Boxó quien a comienzos del siglo XVIII, como consecuencia de los conflictos de la guerra de Sucesión, trasladaría su residencia a Valls, donde trabajó como pasamanero'.

Avanzando en el árbol genealógico, nos aproximamos a Josep Moragas Lleonart, que había nacido en 1768 . Fidel, su padre, tejedor de lana y comerciante de tejidos, había contraído matrimonio con Maria Lleonart, también hija de mercaderes. A comienzos del siglo XIX la fortuna de los Moragas, si tenemos en cuenta las dotes concedidas a las hijas, debía ser notable; entre 1798 y 1806 la suma por este concepto ascendió a 27.000 libras. Josep, a los veinte años, se casó con Rosa Dot Prats, nacida en Manlleu, de una familia cuya actividad estaba relacionada igualmente con el comercio. De este matrimonio nacieron seis hijos: Fidel, Narcís, Josepa, Narcisa, Maria Rosa y Maria Neus, que se desposaría con Josep Figueres, siendo los progenitores de Estanislau Figueres, que Ilegaría a ser presidente de la I República Española. Fidel Moragas Dot, el primogénito y heredero, emparentó con Teresa Tavern y Núñez Pastor, cuyo padre era oficial de la Armada, ingeniero y jefe de la fortaleza de Roses; su abuelo había sido abogado de la corte de Tolosa de Languedoc. La notoriedad de la familia Moragas se acrecentó con los descendientes de Fidel y de Teresa, puesto que su hija Rosa se casaría con Josep Oller, siendo los padres del escritor Narcís Oller; Joana, otra de sus hijas, contraería nupcias con Francesc Yxart, relación de la cual nació Josep Yxart, reconocido historiador, poeta y periodista tarraconense del siglo $\mathrm{XIX}^{10}$. Por último, hacemos referencia a la madre de nuestro personaje,

del Camp de Tarragona a Llatinoamèrica (1778-1833). Tarragona, Port de Tarragona, 2016, pp. 100-107.

8. Olivé Serret, E., Els Moragas. Història íntima d'una família de notables 1750-1868. Tarragona, Diputació de Tarragona, 1998.

9. Olivé Serret, E., Els Moragas. Història íntima d'una família, pp. 41-45.

10. Con respecto a estos personajes ver Rovira Gómez, S. J., "Estanislau Figueras i els Ixart (1851-1873)". Quaderns d'història tarraconense, núm. 8 (1989), pp. 121-129. 
Maria Rosa Moragas Dot, que se casaría con Magí Gatell Porta, hacendado y comerciante de Torredembarra ${ }^{11}$.

\section{La familia Gatell Moragas}

\subsection{Matrimonio entre Magí Gatell y Maria Rosa Moragas}

Magí Gatell había nacido en Torredembarra el 11 de mayo de 1783, era el penúltimo de seis hermanos: Francesca, Anna, Gertrudis, Josep, Magí e Ignasi, resultado del matrimonio entre Francesc Gatell Garcia y Rosa Porta Costa ${ }^{12}$. La boda entre Magí Gatell y Maria Rosa Moragas se celebró el 10 de julio de 1804 en la iglesia de San Juan Bautista de Valls; fue oficiada por Joan Maria González, arcediano de la catedral de Tarragona, y como testigos intervinieron los doctores en teología Bernardino Llopis y Manuel de Lasfuentes, canónigos de la misma catedral ${ }^{13}$.

Magí Gatell, pese a que en el acta de matrimonio constaba de profesión campesino -como su padre-, debía ser un agricultor adinerado, porque en el padrón de Torredembarra de 1838 figuraba como hacendado. En el momento del enlace sus progenitores ya habían fallecido; el padre en octubre de 1786 y la madre, que residía en Valls, en julio de $1800^{14}$. No nos consta que ninguno hiciera testamento, de manera que sólo podemos entrever su posición económica gracias a los capítulos matrimoniales

Con respecto al estatus de Maria Rosa Moragas, en principio, además del ajuar guardado en dos cómodas de caoba, recibió como dote la apreciada cantidad de 7.000 libras barcelonesas ${ }^{15}$. De este matrimonio tenemos constancia del nacimiento de tres hijos: Francesc, Rosa y Fidel, en este orden ${ }^{16}$.

Al ocupar las tropas francesas las tierras del Camp de Tarragona, como consecuencia de la guerra de la Independencia -entre junio de 1808 y agosto de 1813-,

11. Olivé Serret, E., Els Moragas. Història íntima d'una família, pp. 46, 47 y 65 a 67.

12. Arxiu Històric Arxidiocesà de Tarragona (AHAT). Parròquia de Sant Joan Baptista de Valls. Sagramentals. Llibre de matrimonis, del 8 de enero de 1769 al 27 de desembre de 1787, fol.46. Església parroquial de Sant Pere Apòstol de Torredembarra. Sagramentals. Llibre de matrimonis de Torredembarra i Clarà, del 31 de marzo de 1703 al 23 de noviembre de 1802, f. 103 y 128. Llibre de baptismes de Torredembarra i Clarà, del 13 de enero de 1723 al 11 de febrero de 1753, f. 109, 125,142, 153 y 171. Llibre de baptismes de Torredembarra i Clarà, del 2 de enero de 1753 al 19 de noviembre de 1786, f. 26.

13. AHAT. Parròquia de Sant Joan Baptista de Valls. Sagramentals. Llibre de desposoris de la parroquial iglesia de sant Joan Baptista de la vila de Valls que comença als set de janer de 1801 y acaba als 30 de desembre de 1815, essent rector lo doctor Jaume Cesat, f. 195-196.

14. AHAT. Sagramentals. Llibre d'òbits de l'església parroquial de Sant Pere Apòstol de Torredembarra, del 30 de diciembre de 1792 al 25 de diciembre de 1851, f. 162.

15. Olivé Serret, E., Els Moragas. Història íntima d'una família, pp. 65-67.

16. Gracias a Antoni Guasch Bosch, genealogista menorquín, sabemos que en marzo de 1809 y enero de 1811, en la isla también nacieron Josep Joaquim y Josep Melcior, que fallecieron poco después (Arxiu Diocesà de Menorca, Parròquia de Santa Maria de Maó). 
parte de la familia Moragas y, con ella, la de Magí Gatell se trasladó temporalmente a Menorca.

Rosa Moragas y su madre Rosa Dot se instalaron en Mahón. Rosa Moragas falleció el 31 de enero de 1813, como consecuencia de una enfermedad, posible secuela del alumbramiento de Fidel, su tercer hijo. Su marido, por tareas profesionales, se encontraba en Cataluña y no pudo despedirse de ella ${ }^{17}$. El 18 de setiembre de 1811, antes del regreso de Magí a Tarragona, para atender sus negocios, el matrimonio hizo testamento; entonces Rosa tenía 24 años y Magí 28. Ambos esposos se declaraban, respectivamente, usufructuarios de los bienes que poseían e instituían a Francesc como heredero, pero mientras Rosa dotaba a las hijas con 500 libras catalanas, Magí lo hacía con 2.000, además de proporcionarles el ajuar correspondiente. Quedaba especificado que su hija Rosa -como era habitual-, sólo podría acceder al grueso de la herencia en caso del fallecimiento de su hermano ${ }^{18}$. Al redactarse el testamento Fidel aún no había nacido. Desconocemos la fecha exacta del regreso de los Moragas a Cataluña, aunque no sería antes de la retirada del ejército francés, a mediados de 1814. Una carta de Josep Moragas, de comienzos de enero de 1815, dirigida a su yerno, lo confirma. Rosa se estaba recuperando en Barcelona de una enfermedad que la obligaba a guardar cama $^{19}$.

\subsection{La actividad profesional de Magí Gatell y Josep Moragas}

Los documentos notariales de sus antepasados confirman a Magí Gatell como propietario de numerosas fincas, situación de privilegio que se corrobora por el hecho de que disponía de un administrador, Antoni Ferrés, que le ayudaba a gestionar su patrimonio.

Como ejemplo de su iniciativa disponemos de dos contratos de arrendamiento de tierras. El primero se realizó en otoño de 1807, cuando Magí concertó la cesión de la sènia ${ }^{20}$ conocida como l'olla de Blet a Joan Cerdà, "lo casadet". El plazo acordado era por cuatro años, que comenzarían a contarse con la festividad de San Miguel, y el precio estipulado era de 180 libras anuales; se especificaba que se abonarían en metálico y no en vales reales; Magí Gatell, dentro de la finca, se reservaba una pequeña porción de tierra para sus propios cultivos $^{21}$. El segundo arriendo se negoció en julio de 1810; el administrador, en

17. Olivé Serret, E., Els Moragas. Història íntima d'una família, p. 238.

18. Arxiu Històric Provincial de Maó (AHPM). Fons Notarial. Joan Seguí Vidal (1806-1811), f. 441-444.

19. Archivo privado Isabel Morros Rovira (IMR). Carta de Josep Moragas a Magí Gatell. Barcelona, 9 de enero de 1815.

20. Alcover, A. M., Moll, F. de Borja. Diccionari Català-Valencià-Balear. Barcelona, IEC, 2002. Sènia: Pieza de tierra regada artificialmente para cultivar hortalizas.

21. Arxiu Històric de Tarragona (AHT). Fons de la família Moragas (1413-1951). Expedients comercials. Contrato de arrendamiento entre Magí Gatell y Joan Cerdà. 
representación de Magí, firmaba con Josep Roca, agricultor de Creixell, un contrato como "masover"; el pacto incluía cuatro cosechas y se prolongaba hasta 1813. En realidad se trataba de una prórroga, ya que el acuerdo inicial se había pactado años atrás con un abuelo de Roca ${ }^{22}$.

A partir del matrimonio con Rosa Moragas, las labores propias se vieron incrementadas con las que desarrollará junto a la familia vallense. La relación comercial que mantenían suegro y yerno se constata en protocolos notariales y en la numerosa documentación epistolar referida, principalmente, a transacciones de vino y aguardiente. El 5 de abril de 1832, Fidel Moragas, en nombre de su padre Josep, ya fallecido, firmaba ante el notario de Valls Josep Marrugat Ferran una escritura de liquidación de deuda a favor de Magí Gatell. Las cuentas que saldaban se referían a la parte de intereses que pertenecían a Magí por su participación en:

[...] los arriendos de Arbeca y de novenos ${ }^{23}$, como en el subarriendo de novenos de la Mitra de Tortosa, de que fue socio el citado Josep Moragas en los años mil ochocientos cinco a mil ochocientos ocho y demás negocios entre ellos tenidos hasta el dia $[\ldots]^{24}$.

Magí, después del fallecimiento de su esposa, permaneció en Torredembarra, combinando la gestión de sus negocios con los compromisos contraídos con la compañía de su suegro. El 20 de junio, desde Mahón, éste le exhortaba a adquirir 100 pipas de vino tinto del Tarragonès, insistiendo en que fuera de buena calidad y de intenso color oscuro, dado que su destino era Janeyro; en el supuesto de que no pudiera reunir la totalidad del cargamento le recomendaba completarlo con caldos de la zona de El Vendrell, en cuyo caso la calidad se imponía al coste, ya que no le señalaba límite de precio. En setiembre Josep Moragas, de regreso a Barcelona, escribía nuevamente a su yerno para reprocharle que hacía tiempo que no tenía noticias suyas y precisaba conocer el precio de las 100 pipas de vino. Moragas le amonestó a pesar que Magí alegara estar vendimiando ${ }^{25}$.

De la documentación epistolar podemos deducir que Magí Gatell actuaba como corresponsal comercial de la familia Moragas: su participación se orientaba a facilitar información sobre precios, contactar con proveedores, controlar los encargos de vino y su distribución en las mejores condiciones

22. AHT. Fons de la família Moragas (1413-1951). Expedients comercials. Contrato de masovero, Torredembarra, 8 de julio de 1810, firmado por Anton Ferrés y Vicent Fontanilles, representantes de Magí Gatell y Josep Roca, respectivamente.

23. Se refiere al derecho de frutos de este nombre.

24. AHT. Fons de la família Moragas (1413-1951). Expedients comercials. Liquidación de cuentas entre D. Fidel Moragas, comerciante de la presente villa y D. Magín Gatell también comerciante de la de Torredembarra, José Marrugat Ferran, Valls, 5 de abril de 1832.

25. IMR. Cartas de Josep Moragas a Magí Gatell. Barcelona, 31 de enero; Mahón, 22 de junio y Barcelona 30 de setiembre de 1815. 
y, probablemente, garantizar la seguridad de dichas operaciones. La relación entre yerno y suegro se puede calificar de respetuosa, aunque distante.

Mientras, los hijos de Magí Gatell residían en Barcelona con los abuelos maternos: el mayor, Francisquet, con nueve años, manifestaba gran interés en las tareas escolares, hasta el extremo de ser premiado con una medalla por el resultado de sus exámenes ${ }^{26}$.

Tras el fallecimiento, en 1822, del patriarca de la familia Moragas, se prolongaron las relaciones comerciales entre Magí Gatell y sus cuñados Fidel Moragas Dot y su hermano Narcís. Los vínculos familiares prosiguieron con la presencia de los hijos de Magí Gatell en la capital catalana, además de participar en ciertas celebraciones. El 2 de febrero de 1835 Fidel Moragas les invitó a asistir a los actos dedicados a la Mare de Déu de la Candela, patrona de Valls, que aquel año adquirieron una especial relevancia, porque gracias a la intercesión de la Virgen la ciudad se había liberado de una epidemia de cólera $^{27}$. Fidel Moragas, con la presencia de su madre Rosa Dot, su esposa Teresa Tavern, la hermana Maria Neus y otros parientes, deseaba reunir buena parte del grupo familiar ${ }^{28}$.

Al margen de su gestión como comerciante, Magí Gatell debía gozar de un cierto prestigio, sobre todo cuando en 1806 el rey le había nombrado Bayle de Aguas $^{29}$. Blas de Aranza, entonces Intendente General del Ejército y Principado de Cataluña, había presentado el nombramiento al Real Consejo de Hacienda el 4 de agosto de 1804. El cargo tenía jurisdicción sobre la villa de Torredembarra, junto con los términos de Clarà, Tamarit, Ferran y La Riera. La tarea del bayle era cuidar del:

[...] buen regimen y curso de las aguas, haciendo formar sus conductos, diques, puentes, repartimientos con lo demás perteneciente a este encargo, y privando del uso de dichas aguas a las personas que no tubieren título legítimo, conminando a los contractores con la penas regulares $[\ldots]$.

El cargo conllevaba también descubrir e investigar fraudes al Real Patrimonio, referidos a regalías, censos y derechos en el uso del agua. Al bayle le co-

26. IMR. Carta de Josep Moragas a Magí Gatell. Mahón, 22 de junio de 1815.

27. En el año 1834, en Cataluña se produjo una epidemia de cólera. En el Camp de Tarragona fue especialmente intensa; según Eduard Toda, en Reus, entre el primero de agosto y el 3 de octubre de 1834, se produjeron 608 defunciones. Nadal Oller, J. La población española (siglos XVI a XX). Barcelona: Ariel, 1966, pp. 134-138. Para otoño de 1834 Nadal calcula en Barcelona unas 3.869 muertes.

28. IMR. Carta de Fidel Moragas a Magí Gatell. Valls, 28 de enero de 1835.

29. Después de consultar al Consejo Supremo de Hacienda, el 15 de julio de 1747, el Rey decidió restablecer en Cataluña los Tribunals o Pequeños Veguerios de Bayles de Aguas, concediendo a los Intendentes la facultad de nombrarlos. 
rrespondía un porcentaje del importe de las sanciones; que se dividían en tres partes, distribuidas entre el Real Patrimonio, el juez que había enjuiciado el caso y el mismo bayle ${ }^{30}$.

\section{3. Últimas voluntades de Magí Gatell y sus descendientes}

a) Testamento de Magí Gatell

El 9 de octubre de 1842, encontrándose indispuesto, Magí Gatell dictó un nuevo testamento; aunque el 18 de setiembre de 1811, encontrándose en Mahón, ya hubiera redactado otro con su esposa. En el actual, su hijo Francesc conservaba el carácter de heredero. A Fidel, el emigrante americano, le correspondían 4.000 libras, de las cuales 3.000 procedían de la legítima paterna; 500 de la legítima materna y otras 500 tenían como fin la adquisición de ropa. El testamento establecía que dichas cantidades se abonarían por medio del heredero. La primera entrega sería de 1.500 libras y el resto lo percibiría de año en año, a razón de 500 libras. De esta suma, en el momento de marchar hacia América, Fidel había recibido 500 libras.

A Rosa le correspondían también 4.000 libras por los mismos conceptos, además de dos baúles y una caja con la ropa blanca de su madre. Para tomar posesión de todo ello le era imprescindible contraer matrimonio, de modo que en el día de la boda recibiría 2.000 libras y el resto, 500 libras de año en año. Si finalmente permanecía soltera, podía seguir en el domicilio familiar, junto a su hermano Francesc, y si decidía abandonarlo, mientras siguiera en ese estado, dispondría de cinco reales de vellón diarios para su manutención.

Para Francesca Montserrat, la criada, Magí Gatell determinó que, mientras realizara las labores domésticas, fuera atendida en sus necesidades, pero si su deseo era retirarse se la gratificara, en concepto de alimento, con 11 cuartos diarios, que se le entregarían de por vida, por tercias anticipadas ${ }^{31}$.

El 19 de octubre, Magí Gatell modificó el testamento con respecto a su hija. Rosa podría disponer de las 1.500 libras aunque no se casara, y al ajuar le añadió un cubierto de plata, unos pendientes de bellugons y rubíes, unos brazaletes de oro, ropa y el suministro de productos de su cosecha ${ }^{32}$. Las joyas añadidas a su legado procedían de los bienes de su madre que, a petición del heredero, aparecen detallados en el inventario realizado en 1842, después del fallecimiento de Magí. Con respecto al mobiliario y pertenencias, había

30. AHT. Fons de la família Moragas (1413-1951). Expedients comercials. Magí Gatell, Torredembarra 1808-1830. Certificación del notario Jaume Barado, Torredembarra, 9 de diciembre de 1824.

31. Arxiu Comarcal Baix Penedès (ACBP). Fons notarial. Francesc Barado. Manual de 1842. Testamento de Magí Gatell, f. 22.

32. ACBP. Fons notarial. Francesc Barado. Manual de 1842. Codicilo de Magí Gatell, f. 24. 
dos baúles repletos de vestidos y las dos cómodas citadas anteriormente, que guardaban diversas alhajas y complementos:

Una capsa ab unas arrecadas llargas de vellugons de pedras vermeIlas; una anell Ilarch de pedra blava, ab tres diamants al mitg, y tot lo ruedo tambe de diamants; dos brasalets ab unas soguillas finas y dos corts tot de or; uns rosaris ab sa creu tot de madre perla de set denas encadenats de or; un vestit y una talla de setí blanch brodat de or; altre de seda negre y altre de crespó $^{33}$.

Magí Gatell falleció en Torredembarra el 8 de noviembre de 1842; contaba 59 años $^{34}$.

b) Francesc Gatell Moragas, el heredero

Francesc Gatell nació el 1 de marzo de 1806 y fue bautizado en Torredembarra por fray Josep Moragas, superior del Convento de Religiosos Mínimos de Valls ${ }^{35}$. Se aprecia en la familia una preocupación por dotarle de una adecuada formación, ya que en 1817 -entonces tenia 11 años- estudiaba en la Escuela Pía de Santa Anna de Mataró, un destacado centro educativo de Cataluña ${ }^{36}$. El director era Vicente Fornaguera, quien el 2 de febrero firmó haber recibido de Josep Moragas la suma de 183 libras 18 sueldos y 5 dineros; de dicha suma, 136 libras 17 sueldos y 6 dineros correspondían al importe de seis meses de permanencia en la escuela, hasta julio ${ }^{37}$.

Francesc contrajo matrimonio en dos ocasiones; en 1844, con Anna Maria Borrull Aleu, natural de Torredembarra, con la que no tuvo descendencia. La repentina defunción de su esposa en 1850, y para asegurar la sucesión, hizo

33. Arxiu Històric Provincial de Maó (AHPM). Fons Notarial. Joan Seguí Vidal (18061811), fol. 441-444. Testamentos de Rosa Moragas y Magí Gatell, 18 de setiembre de 1811. Fons notarial. Francesc Barado, 1842. Inventario de bienes,1 de diciembre de 1842, f. 142.

34. AHAT. Sagramentals. Llibre d'òbits de l'església parroquial de Sant Pere Apòstol de Torredembarra, del 30 de diciembre de 1792 al 25 de diciembre de 1851.

35. AHAT. Sagramentals. Llibre de Baptismes de l'església parroquial de Sant Pere Apòstol de Torredembarra, del 1 de enero de 1787 al 7 de diciembre de 1806. Emparentado por parte de su madre, aunque ignoramos el grado. El profesor Enric Olivé, en el árbol genealógico de la página 424 del libro ya citado, cita a Fidel, fraile mínimo estudiante en Cervera que, a pesar de la falta de coincidencia del nombre, podría tratarse de la misma persona.

36. Florensa Parés, J., Tres-cents anys d'Escola Pia de Balaguer. Barcelona: 1999, p. 50. En las Escuelas Pías se impartían conocimientos de lectura, escritura y aritmética; gramática latina y retórica; la de Mataró, fundada en el primer tercio del siglo XVIII, destacaba por la enseñanza de la aritmética. Picanyol, LI., "Los escolapios en la archidiócesis de Barcelona". Analecta sacra tarraconensia: Revista de ciències historicoeclesiàstiques, núm. 37 (1964), pp. 467-489. A finales del siglo XVIII un millar de alumnos estudiaban en sus aulas.

37. AHT. Fons de la família Moragas (1413-1951). Correspondència familiar. Cuenta de gastos de Francesc Gatell, Mataró, 2 de febrero de 1817. 
que a finales de 1866 -entonces tenía 60 años-, se desposara con Constança, una joven de 30, hija del licenciado en cirugía Gaietà López, originario de la Seu d'Urgell, y de Rosalia Malet, de Torredembarra; de este enlace nacieron dos hijos, que fallecieron poco después ${ }^{38}$.

Francesc Gatell era una persona reconocida económica y socialmente. En 1842 era tercer regidor del Ayuntamiento ${ }^{39}$. En 1857 formaba parte de la junta de gobierno de la sociedad Crédito Mobiliario Barcelonés, cuya finalidad era conseguir capitales para fomentar inversiones, siendo la más importante la construcción de ferrocarriles, un medio de transporte que estaba en pleno auge. Cuando en el mismo año se constituyó la Compañía del Ferrocarril de Tarragona a Barcelona, Francesc participó con 10 acciones $^{40}$.

La trayectoria profesional de Francesc Gatell siguió los pasos de su padre: la numerosa correspondencia comercial con Fidel Moragas Dot confirma la relación que mantuvo con sus parientes. Tampoco se perdió el contacto familiar: la madrina de su primer hijo fue Teresa Tavern, esposa de Fidel Moragas, mientras que Narcís Moragas fue el padrino del segundo ${ }^{41}$.

Como heredero, Francesc Gatell recibió la parte más sustanciosa del patrimonio familiar. El inventario realizado incluía los bienes de la residencia del carrer Ample y las fincas de Torredembarra y Creixell. No entraremos en el detalle de los enseres, pero sí detallaremos los bienes inmuebles, así como los capitales, asientos de crédito y deuda. Por lo que se refiere a las fincas, en total sumaban 27: en Torredembarra se localizaban 11, en Creixell 12, en Clarà tres y una en La Pobla de Montornès. Pese a que comprendían una apreciable superficie -más de 100 jornales-, los cultivos: viñas, olivos y algarrobos, eran todos de secano, por lo cual tenían un valor relativo ${ }^{42}$.

38. AHAT. Sagramentals. Llibre de Baptismes de l'església parroquial de Sant Pere Apòstol de Torredembarra, del 8 de diciembre de 1806 al 30 de diciembre de 1836. También el de 4 de enero de 1852 al 26 de diciembre de 1869. Llibre d'òbits de l'església parroquial de Sant Pere Apòstol de Torredembarra, del 7 de enero de 1852 al 29 de diciembre de 1874. Llibre de baptismes, del 1 de enero de 1870 al 18 de diciembre de 1881 .

39. ACBP. Fons notarial. Francesc Barado, Manual de 1842. Torredembarra, 21 de febrero de 1842.

40. Català Massot, LI., "Els torrencs i la construcció del ferrocarril". Recull de Treballs, 14 (2013), pp. 85-115. Del mateix autor: 150 anys del ferrocarril a Torredembarra. Torredembarra: Centre d'Estudis Sinibald de Mas, 2015. En relación a la implantación del ferrocarril en la demarcación, Català Massot, LI., Brulles Eneriz, LI., L'Estació de Ferrocarril d'Altafulla-Tamarit (1865-2015). Altafulla, Centre d'Estudis Altafulla, 2015. Con respecto a la Compañia del Ferrocarril de Tarragona a Barcelona veure Pascual Domènech, P., Los caminos de la era industrial. La construcción y financiación de la Red ferroviaria catalana (1843-1898). Barcelona, Edicions de la Universitat de Barcelona, 1999, pp. 136-142.

41. AHAT. Sagramentals. Llibre de Baptismes de l'església parroquial de Sant Pere Apòstol de Torredembarra, desde el 4 de enero de 1852 al 26 de diciembre de 1869 y desde el 1 de enero de 1870 al 18 de diciembre de 1881.

42. ACBP. Fons notarial. Francesc Barado. Manual de 1842. Inventario de bienes de Magí Gatell, de 30 de novembre de 1842, f. 137-142. 
TABLA. Fincas heredadas por Francesc Gatell. Términos de Torredembarra, Clarà, Creixell y La Pobla de Montornès.

\begin{tabular}{|l|c|l|l|}
\hline \multicolumn{1}{|c|}{ Finca } & $\begin{array}{c}\text { Superficie } \\
\text { Jornales }\end{array}$ & \multicolumn{1}{|c|}{$\begin{array}{c}\text { Situación } \\
\text { o partida }\end{array}$} & \multicolumn{1}{|c|}{$\begin{array}{c}\text { Observaciones/ } \\
\text { Cultivo }\end{array}$} \\
\hline Casa entre medianeras & -- & Calle Ample & Tenia tres portales \\
\hline Solar cerrado & -- & Fora vila & 15 quintales de leña \\
\hline Pieza de tierra campa & 4 & Moreres & $\begin{array}{l}\text { Frutales, casa, noria, } \\
\text { 2 lavaderos }\end{array}$ \\
\hline Viña & 1 & Moreres & 1 olivo, 4 arbequinas \\
\hline Pieza de tierra & 0,5 & Moreres & 2 arbequinas \\
\hline Viña & 8 & Portadora & Arbequinas y olivos \\
\hline Pieza de tierra, roquedal & 10 & Els Munts & 1 Higuera, noria y \\
\hline Pieza de tierra campa & 2 & Parellades & Algarrobos \\
\hline Pieza de tierra & 3 & Mas Tarrasa & Algarrobos \\
\hline Pieza de tierra & 1,5 & Paret Blanca & \\
\hline Pieza de tierra, roquedal & $2 / 8$ & Capella & Algarrobos y olivos \\
\hline Viña & 12 & Clot del Castell, Pobla & Montornès \\
\hline Viña /Algarrobo & 3,5 & Glaietes, Clarà & \\
\hline Viña/tierra campa/prado & 3,5 & Sadolla, Clarà & \\
\hline Almacén y corral & & Clarà (cerca playa) & \\
\hline Casa & & C/ França, Creixell & Corral y huerta \\
\hline Tierra de secano & 1 quartót4 & Les Cases, Creixell & \\
\hline Una era y dos paradas & 1 quartó & Creixell, acceso a la villa & \\
\hline Pieza de tierra campa & 3 & Camí de Mar, Creixell & Noria y lavadero \\
\hline Pieza de tierra, olivera & 3 & Basseta, Creixell & \\
\hline Viña & 6 & Alzina dolça, Creixell & \\
\hline Viña, olivos, Algarrobo & 5 & Camp de l'Era, Creixell & \\
\hline Algarrobos & 1 & Tarré, Creixell & \\
\hline Viña, olivos & 10 & Carosa, Creixell & \\
\hline Olivos & 1,5 & Morisques, Creixell & \\
\hline Viña, olivos, algarrobos & 10 & Morisques, Creixell & \\
\hline Viña, algarrobo, carrascal & 14 & Coma i Pujol, Creixell & \\
\hline
\end{tabular}

43. Villuendas Gibert, E., "Onomàstica de la vila de Torredembarra al segle XIX". Butlletí de la Societat d'Onomàstica, XVII, (1984), pp. 39-44.

Moreu-Rey, E., "Unes dades inèdites de la història de Torredembarra". Miscel/lània Fort $i$ Cogul: història monàstica catalana, història del Camp de Tarragona. Publicacions de l'Abadia de Montserrat, 1984, pp. 253-257.

44. Probablemente se refiere a la cuarta parte del jornal. El Diccionari Català-ValenciàBalear para las zonas del Pla de Llobregat, Igualada, Mataró, Penedès y Vilanova i la Geltrú lo calcula como la cuarta parte de la mujada, equivalente a 506'25 canas cuadradas o 12'24 áreas. 
En cuanto a capitales, se contabilizaron 10.400 libras catalanas: 7.000 procedían de la dote de su madre Rosa Moragas, 2.000 correspondían a un incremento de dicha dote, concedido por su padre Josep, y las 1.400 restantes también se debían a un aumento de dote, en este caso por parte de su esposo Magí. En el apartado de contratos financieros constan dos asientos de crédito y 11 de deuda. Los primeros correspondían a un censal de 100 libras y pensión anual de tres libras, y a una suma de 930 libras y 3 sueldos que acreditaba Magí Gatell, de Fidel Moragas, de una escritura de liquidación de cuentas. Los censos se referían a miembros del estamento nobiliario, el conde de Santa Coloma o Joaquim de $\mathrm{March}^{45}$, y a instituciones religiosas: monasterio de Santes Creus, capilla de Sant Miquel de la villa del Pla, comunidad de Sant Jaume de Barcelona, beneficio de Sant Antoni de Pàdua de La Pobla de Montornès, cabildo de la catedral de Tarragona, rectoría de Creixell o beneficio de Santa Rosalia de Torredembarra ${ }^{46}$.

\section{c) Rosa Gatell i Moragas}

Rosa Gatell nació en Tarragona el cinco de octubre de 1807, antes de que la familia se trasladara a Mahón ${ }^{47}$. Su presencia en Torredembarra pronto quedó difuminada. En 1821 la encontramos en la lista de comulgantes de la parroquia, en el domicilio paterno. Cabe preguntarse si residía con sus abuelos maternos o con alguna de sus tías, como sucedió con sus hermanos. El 11 de noviembre de 1839 estableció capítulos matrimoniales con Faustino de Aguirre, capitán de caballería.

Faustino de Aguirre Ventosa nació en San Vicente de la Sonsierra (La Rioja), el 17 de febrero de $1797^{48}$; con 42 años de servicio tenía una larga trayectoria. En 1815 ingresó en el Real Cuerpo de Guardias de la Persona del Rey, lo cual fue posible por su condición de caballero, imprescindible para acceder al servicio del monarca ${ }^{49}$. En enero de 1821, a las órdenes del general Juan de la Cruz Mougeón, partió con destino a Nueva Granada, para contener las sublevaciones independentistas ${ }^{50}$. El 24 de mayo de 1822, con el Regimiento de Lanceros,

45. Congost, R., "La família Safont, el comte de Santa Coloma i la revolució liberal". Recerques: història, economia, cultura, 22 (1989), pp. 83-92. Rovira Gómez, S. J., Els March darrers senyors de Creixell i Roda de Berà. Valls, Cossetània, 2003.

46. ACBP. Fons notarial. Francesc Barado. Manual de 1842. Inventario de los bienes de Magí Gatell, de 30 de noviembre de 1842, f. 137-142.

47. AHAT. Parròquia de Santa Maria de la Catedral, Tarragona. Sagramentals. Llibre XXI de Baptismes, de 01-01-1807 a 14-04-1811.

48. Archivo Parroquial de la iglesia de Santa María de San Vicente de la Sonsierra. Libro de bautismos, 1797, Rector Pedro Ramón Ramírez, f. 77.

49. Archivo General Militar de Segovia (AGMS). Secretaria de Estado y de Despacho de la Guerra. Sección 1ª . Legajo A-442. Expediente. 1078. Formulario de ingreso en la Guardia Real.

50. Vega Viguera, E. de la, Cinco Capitanes Generales de Andalucía eran sevillanos. Sevilla, Separata del Boletín de la Real Academia de Buenas Letras de Sevilla, 1987, pp. 82- 
intervino en la batalla de Pichincha. La derrota de las tropas realistas ante el ejército del general Antonio José de Sucre significó la independencia de los territorios vinculados a la Audiencia de Quito ${ }^{51}$.

De regreso a la Península obtuvo diversos empleos y también permaneció en excedencia, hasta que el 10 de mayo de 1834 fue nombrado teniente del Regimiento de Caballería del Infante $4^{\circ}$ de Línea ${ }^{52}$. Las guerras carlistas fueron la causa de su llegada al Principado y de la relación con Rosa Gatell Moragas. Entre 1834 y 1840, el Regimiento del Infante participó en diversas acciones en localidades del corregimiento de Tarragona: Alcover, Montagut, Sarral, Rocafort de Queralt, Montblanc, Espluga de Francolí; también en Sant Joan de les Abadesses y Sant Quirze de Besora, y principalmente en las batallas de Gra, Peracamps y en el sitio de Solsona ${ }^{53}$. Será en estas últimas operaciones donde destacará Aguirre. El 28 de junio de 1835 combatía cerca de Camprodon, enfrentándose a la partida del cura Pere Massanas, a la que hicieron huir ${ }^{54}$. El 1 y el 2 de mayo de 1837, siendo escolta de caballería en el cuartel general del Barón de Meer, General en Jefe del Ejército de Cataluña, intervino en las acciones de Perecamps y Sant Pere de Padullers. Y el 12 de junio participaba en la batalla de Gra, por la que fue condecorado con la Cruz de San Fernando de $1^{\text {a }}$ Clase ${ }^{55}$.

En noviembre de 1839 -como se ha dicho- firmaba los capítulos matrimoniales con Rosa Gatell. Sin embargo, en el redactado del testamento de 1842, su padre no contempla que se hubiera celebrado el enlace, puesto que una de

92. Juan de la Cruz Mougeón llegaba como Capitán General y Presidente de la Audiencia de Quito, con la promesa de ser nombrado Virrey en cuanto ocupase la capital.

51. Esteves González, E., Batallas de Venezuela, 1810-1824. Caracas, Editorial CEC, 2004, pp. $169-171$.

52. Nieva, J. M. de, Decretos del Rey Nuestro Señor Fernando VIl y Reales Órdenes, Resoluciones y Reglamentos Generales expedidos por las Secretarias del Despacho Universal y Consejos de S. M. desde $1^{\circ}$ de enero hasta fin de diciembre de 1828. Tomo XIII. Madrid: Imprenta Real, 1829. Real Decreto de Organización del Ejército, 31 de mayo de 1828, p. 135. Según el artículo 42, el apartado referido a caballería determinaba la creación de cinco regimientos de línea y siete de ligera. Los de línea eran: Rey $1^{\circ}$ de Línea, Reina $2^{\circ}$, Príncipe $3^{\circ}$, Infante $4^{\circ}$ y Borbón $5^{\circ}$.

53. Soto y Abbach, Conde de Clonard, Serafín $M^{a}$ de. Historia Orgánica de las Armas de Infantería y Caballería Españolas, desde la creación del ejército permanente hasta el día. Tomo XVI. Madrid, 1851-1859?. Sexta Sección. Regimientos de Caballería de Línea. Infante, p. 349. En el historial de las campañas de este regimiento observamos que, desde 1642 fecha de su creación, su presencia en Cataluña fue frecuente. En 1643 y 1644 estaba en Lleida; durante la guerra de Sucesión intervino en el sitio de Barcelona de 1714; después de participar en las guerras de Italia, actuó en la Guerra Gran: batalla de Masdeu, ocupación de Banyuls, Cotlliure, Portvendres y en Bellver.

54. Llongarriu Montsalvatge, R., "Dos eclesiàstics guerrillers a la Primera Guerra Carlina". Annals del Patronat d'Estudis Històrics d'Olot i Comarca, (1995), pp. 109-116.

55. En Gra, actualmente núcleo agregado a Torrefeta y Florejacs (La Segarra), las tropas realistas de Ramón de Meer y de Diego León derrotaron a los carlistas de Ros de Eroles. La distinción se le concedió por Real Orden de 13 de agosto de 1837. 
las cláusulas manifestaba que Rosa podía disponer de parte de la herencia, independientemente de que contrajera o no matrimonio. En todo caso éste pudo celebrarse con posterioridad al óbito de Magí Gatell.

\section{Fidel Gatell Moragas}

a) Infancia y juventud

Fidel Gatell nació el 25 de noviembre de 1812 en Mahón, donde fue bautizado en la parroquia de Santa María ${ }^{56}$. Después del fallecimiento de su madre, cuando en la Península se normalizó la situación política, regresó con el resto de sus parientes a Cataluña.

En las misivas intercambiadas entre las familias Gatell y Moragas, se han localizado justificantes de diversos gastos de Fidelet -así le llamaban familiarmente- por adquisición de vestuario, por su educación y otros dispendios, que nos permiten asegurar que una parte de su adolescencia debió transcurrir en Barcelona, con su tía Maria Neus Moragas. Periódicamente, la cuñada de Magí Gatell le remitía una detallada relación del coste de manutención de su hijo. A comienzos de mayo de 1830, cuando Fidel tendría 17 años, Maria Neus le envió una misiva con diversos importes, resultado de la compra de unos zapatos, papel y lavar y planchar la ropa. Correspondientes a 1831 y 1832, disponemos de dos notas similares en las que se incluye la suma de 30 reales, relativa al recibo mensual del profesor de francés ${ }^{57}$.

Al Ilegar a la edad adulta, probablemente a causa de un futuro profesional incierto, por verse relegado en el derecho de primogenitura, y quizás también para escapar de la influencia de la familia materna, se dirigió al otro lado del Atlántico. Su proyecto fue compartido por muchas otras personas: Martín Rodrigo se refiere "al flux incessant de catalans que van emigrar a Cuba i a Puerto Rico amb la intenció de fer les Amèriques, o sia amb la voluntat de tornar". Muchos de ellos antes de cruzar el océano residieron en Barcelona, como fue el caso de Josep Xifré Casas, natural de Arenys de Mar; los hermanos Aleix y Manuel Vidal Quadras, Gaudenci y Rafael Masó Pascual, y Josep Amell Bou, los cinco nacidos en Sitges; Joan Güell Ferrer y Esteve Gatell Roig, de Torredembarra; Andreu Bru Puñet, de La Selva del Camp; Josep Canela Raventós, de Reus; Onofre Viada Balanzó, de Mataró; Joan Puig Mir, de Vilassar de Mar; Salvador Vidal Cibils, Josep Carbó Martinell y Joan Anglada Carreras, de Sant Feliu de Guíxols;

56. Archivo General de Indias (AGI). Indiferente General, 2159. Expediente de Fidel Gatell Moragas solicitando viajar a Puerto Rico. Certificación de nacimiento. Agradezco la localización del expediente a Ginés Puente Pérez.

57. IMR. Carta de Maria Neus Figueres Moragas a Magí Gatell. Nota de los gastos producidos por Fidel Gatell, Barcelona, 8 de mayo de 1830; otra nota similar comprende desde el 13 de mayo a 24 de diciembre de 1831 y otra del 20 de marzo al 25 de mayo de 1832. 
Josep Antoni Salom, Francesc Gumà Ferran y Jaume Samà Martí, de Vilanova i la Geltrú ${ }^{58}$.

El 23 de octubre de 1834 Fidel iniciaba los trámites para pedir a las autoridades licencia para trasladarse a Puerto Rico, concretamente a Mayagüez; petición que era aprobada dos semanas después ${ }^{59}$.

En enero de 1835 se encontraba en Barcelona, a la espera de zarpar hacia América. El día 17, viernes, escribía a su padre manifestándole que hacía dos días que debían haber partido, siendo la causa de la demora la enfermedad de otro pasajero, un tejedor de Tarragona Ilamado Lluïset. Ignoraba cuando se produciría la partida, pero esperaba que no fuera más allá del domingo, pues se preveía que dicho día saliera una goleta hacia Puerto Rico. Al mismo tiempo le daba instrucciones para que entregara a los señores Tusquets siete pesetas que le habían prestado, quizá para gastos de viaje. Los Tusquets eran una familia de comerciantes de Barcelona, con quienes tenían muy buena relación, ya que además de otras cuestiones veraneaban en Torredembarra. Finalmente Lluïset se quedaría en tierra, lo cual a Fidel le produjo cierta tristeza, porque habría podido ser una buena compañía ${ }^{60}$.

En el momento de la despedida, su padre le había advertido que en Málaga no se descuidara, pues había gente peligrosa: gente de puñal. Fidel, con una mentalidad más abierta, pensaba que se encontraría con personas de todo tipo y que si alguien no busca pelea no la encuentra ${ }^{61}$.

El 30 de enero aún permanecía en Barcelona, aunque el día anterior había embarcado en un bergantín y ahora sí veía cercana la partida ${ }^{62}$. Finalmente se izaron las velas el 1 de febrero. La navegación por el Mediterráneo se prolongó hasta el día 12, entrando a las once de la mañana en el puerto de Málaga, después de -según propias palabras- un pesadísimo y horroroso viaje. Las tres primeras jornadas habían sido de calma, pero el día 4, tras alcanzar el cabo de San Antonio, tuvieron que anclar delante de la costa de Denia, a causa de un vendaval. A partir de este momento el mareo ya no le abandonó, a pesar de comer sólo lo imprescindible. Sin embargo lo peor aún estaba por llegar, pues seis días más tarde, cuando ya avistaban Málaga, empezó a soplar un viento de poniente intensísimo, que los obligó a derivar, quedando a merced de las olas y refugiándose finalmente en Almería.

58. Rodrigo Alharilla, M., Indians a Catalunya: Capitals cubans en l'economia catalana. Barcelona: Fundació Noguera-Pagès Ed., 2007, pp. 263-264.

59. AGI. Indiferente General, 2159. Expediente de Fidel Gatell Moragas solicitando viajar a Puerto Rico.

60. IMR. Carta de Fidel Gatell Moragas a Magí Gatell. Barcelona, 17 de enero de 1835.

61. IMR. Carta de Fidel Gatell Moragas a Magí Gatell. Barcelona, 17 de enero de 1835.

62. IMR. Carta de Fidel Gatell Moragas a Francesc Gatell Moragas. Barcelona, 30 de enero de 1835. Esta debió ser la última carta que escribió antes de abandonar Cataluña; le encargaba a su hermano que le despidiera de su padre y hermana. 
Así lo explicaba Fidel:

[...] repetidas veces nos vimos sumergidos y sepultados debajo de las olas mas puedo asegurar que como fue de dia lo sufria todo con la mayor tranquilidad de Espíritu y valor spre en cubierta pero amarrado con una cuerda $\mathrm{p}^{\mathrm{a}}$ que el viento no se me llevase pues corria menos riesgo arriva que no que me hubiese quedado en la Camara la que estava inundada $[\ldots]^{63}$.

La tempestad había durado ocho horas. Por fin, el día 10, "fiesta de Santa Escolástica que no se me olvidará", fondearon en Almería. Sin desembarcar, a las nueve de la noche y con la mar en calma, reemprendieron el viaje y aún no había transcurrido una hora cuando de pronto comenzó de nuevo un viento tan fuerte que se vieron obligados a navegar sin velas, ni boneta ni cangreja, decía.

[...] andavamos por devajo las estrepitosas olas, el barco todo virado y las continuas aclamaciones de todos los marineros la oscuridad de la noche y el terrible ruydo del barco, no puedo menos de decirle que habia consentido ya perecer y que ya habia preparado mi alma, contando ya no existir [...] Que cuadro! Que espectáculo por el que hace su primer viaje! $[\ldots]^{64}$.

Al llegar a Málaga, como disponía de tiempo, aprovechó para escribir a sus hermanos. Valoró su estancia en la ciudad andaluza como muy satisfactoria, pese a la opinión contraria que le merecía: "[...] Estamos a la tierra de Dios, país el mas escandaloso del mundo, pues al que tiene un poco de vergüenza se ve privado de andar por las calles [...." $]^{\prime 65}$.

Antes de partir, conocidos de su familia le proporcionaron numerosas cartas de recomendación; eran tantas que, bromeando, comentaba que un Correo Gavinete $^{66}$ no llevaba tanta correspondencia como él. Aprovechar las influencias era una práctica no sólo habitual, sino imprescindible para triunfar profesionalmente; en aquella sociedad endogámica del siglo XIX, una carta de presentación significaba ampliar las expectativas, no sólo en el aspecto comercial, sino también para acceder a los círculos familiares más íntimos.

Una de estas misivas le permitió ser recibido por Monsieur Double, comerciante francés establecido en Málaga, poseedor de buenos contactos tanto

63. IMR. Carta de Fidel Gatell Moragas a Magí Gatell. Málaga, 12 de febrero de 1835.

64. IMR. Carta de Fidel Gatell Moragas a Magí Gatell. Málaga, 12 de febrero de 1835. En la postdata saluda a sus hermanos y promete escribirles, con mayor tranquilidad, antes de partir de la ciudad andaluza.

65. IMR. Carta de Fidel Gatell Moragas a Francesc y Rosa Gatell. Málaga, 16 de febrero de 1835.

66. Diccionario de la Lengua Española (DLE). Correo de gabinete: El que lleva rápidamente correspondencia oficial al extranjero. 
en Mayagüez, en la costa oeste de la isla de Puerto Rico, como en la danesa de Saint Thomas. El domingo por la noche fue invitado a una tertulia, aunque tuvo que retirarse temprano -hacia las 10-, por tener que pernoctar a bordo. Fidel quedó prendado de las dos hijas del señor Double, ante las cuales pudo presumir de sus conocimientos de lengua francesa, que había adquirido en Barcelona $^{67}$.

Cuando al inicio de este trabajo nos referíamos a los Moragas, decíamos que eran una familia de comerciantes en el sentido más amplio. Pues bien, como anécdota puede resultar singular comentar que, mientras se encontraba en Málaga, una embarcación había zarpado en dirección a Tarragona y Fidel lamentaba no haber tenido suficiente liquidez para comprar patatas y enviarlas a Cataluña. La escasez de dinero estaba relacionada con el temor de su padre, por la supuesta inseguridad de la ciudad malagueña. También lamentaba no haber traído una pacotilla ${ }^{68}$ de flores, pues podía haber hecho un buen negocio: "[...] estoy seguro que en Málaga se ganaría mucho dinero pues estan muy en uso pues hasta las que venden el pescado siempre van muy enramadas $[\ldots]^{\prime \prime 69}$.

Al final de la carta saludaba a su familia de Valls, con la que mantenía una buena relación, especialmente con su abuela y tíos. Había calculado que el bergantín en el que viajaba estaría de regreso a Barcelona hacia abril y sugería a sus hermanos que aprovechasen la circunstancia para escribirle y mandarle algunos pares de medias de hilo, muy adecuadas para el clima con que se encontraría: "[...] ya sabéis es tierra que se suda mucho $[\ldots]]^{\prime 70}$.

El 21 de febrero zarparon de Málaga, pero aún no habían navegado cinco leguas cuando comenzó a soplar un viento fuerte de poniente que les obligó a regresar a puerto; mientras no virara a levante permanecerían en tierra. La tristeza que había sentido por ser el único pasajero se disipaba, ya que tanto el capitán como la tripulación le dispensaban buen trato. Durante los primeros días de su presencia en Málaga, como resultado del mareo producido por la tormenta, tuvo una ligera indisposición que le obligó a seguir una dieta, pues su estómago sólo toleraba el caldo: "[...] creo que si ahora no aborrezco las gallinas no las aborreceré nunca $[. . .]^{\prime \prime}$. En general tenía buena opinión de los alimentos que le servían, sobre todo por lo que se refiere al pescado ${ }^{71}$.

67. IMR. Carta de Fidel Gatell Moragas a Francesc y Rosa Gatell. Málaga, 16 de febrero de 1835.

68. DLE. Pacotilla: Porción de géneros que los marineros u oficiales de un barco pueden embarcar por su cuenta, libres de flete.

69. IMR. Carta de Fidel Gatell Moragas a Francesc y Rosa Gatell. Málaga, 16 de febrero de 1835.

70. IMR. Carta de Fidel Gatell Moragas a Francesc y Rosa Gatell. Málaga, 16 de febrero de 1835.

71. IMR. Carta de Fidel Gatell Moragas a Magí Gatell. Málaga, 23 de febrero de 1835. Relata también haber recibido nuevas cartas de recomendación, en este caso de la familia Flaquer. 
La misiva siguiente estaba fechada el ocho de abril, después de su llegada a Puerto Rico, concretamente a Mayagüez. Habían transcurrido siete semanas desde que había salido de Barcelona; más de cinco habían sido de navegación y once días correspondían a la permanencia en Málaga.

El viaje por el Atlántico tampoco fue plácido, ya que al transitar delante de las Islas Canarias se encontraron con otro temporal. Finalmente, antes de desembarcar, estuvieron cuatro días "en observación". Recordemos que por esta época era frecuente la presencia de epidemias como el cólera o la fiebre amarilla; como prevención, las ciudades portuarias exigían a las embarcaciones disponer de pasaportes sanitarios y guardar cuarentenas, lo cual producía a veces serias molestias entre pasajeros y comerciantes.

\section{b) Puerto Rico}

Desde finales del siglo XVIII, con el fin de mejorar la administración colonial e incentivar la economía, la dinastía borbónica había realizado una serie de reformas. En las Antillas sirvieron para preservar antiguos privilegios, que habrían podido desaparecer de no haberse hecho concesiones. En Puerto Rico, esta legislación, junto con el nuevo mapa político que se dibujaba en el Caribe después de la independencia de los Estados Unidos y de Haití y de la emancipación de Hispanoamérica, permitió que la isla alcanzara un notable protagonismo. La llegada de hacendados, huyendo de las Antillas francesas y de las antiguas colonias españolas, el fomento de la producción de azúcar y el aumento de los precios contribuyeron a este impulso ${ }^{72}$.

Entre 1815 y 1825, las demarcaciones costeras de Ponce, Mayagüez y Guayama pasaron de una economía de subsistencia a una de mercado. La Real Cédula de 10 de agosto de 1815, conocida como la Cédula de Gracias, abrió, durante quince años, el comercio de la isla con las naciones amigas y facilitó la llegada de emigrantes extranjeros de estas naciones, siempre que profesaran la religión católica. Si eran de raza blanca se les concedían a perpetuidad cuatro fanegas y dos séptimos de tierra, y la mitad más por cada esclavo que aportasen ${ }^{73}$.

Se permitió introducir maquinaria y herramientas agrícolas; se abolieron antiguos impuestos, como la alcabala y diezmos eclesiásticos, que fueron sustituidos por otro de importe equivalente, Ilamado subsidio; finalmente se concedió permiso para comprar esclavos - pese a los acuerdos entre España e Inglaterra de 1817, 1835 y 1845 de prohibir la esclavitud-, lo cual resultó decisivo para

72. Lavallé, B., Naranjo, C., Santamaría, A., La América Española (1763-1898). Economía. Madrid, Editorial Síntesis, 2002, pp. 154-156.

73. Guiven Flores, C. "La Real Cédula de Gracias de 1815 para Puerto Rico, instrumento jurídico de reformas y cambios en la primera mitad del siglo XIX". Anuario Mexicano de Historia del Derecho, 8 (1996), pp. 171-187. 
el relanzamiento económico y contribuyó a preservar el dominio español ${ }^{74}$. Las concesiones de la Real Cédula ayudaron a atraer a la élite criolla y a alejarla de la tendencia independentista. La llegada de esta fuerza de trabajo y la de comerciantes, militares, eclesiásticos y refugiados políticos produjeron un importante aumento demográfico. A comienzos del siglo XIX, Puerto Rico tenía 155.427 habitantes: casi la mitad eran de raza blanca y se distribuían en 38 partidos. En 35 años había triplicado el número. Hacia 1827 se situaba en unos 300.000 y en 1834 se alcanzaron los 360.000. De las localidades que frecuentó Fidel Gatell, Mayagüez podía tener unos 16.000 habitantes, Ponce 13.600 y San Juan 11.500. La mayor parte de estos inmigrantes se movieron por intereses comerciales: muchos tenían familiares ya establecidos en la isla y contribuyeron a reforzar sus empresas creando verdaderas redes ${ }^{75}$.

Durante el siglo XIX, los cultivos predominantes fueron los de la caña de azúcar, el café y el tabaco. A mediados de la centuria Puerto Rico se convirtió en el segundo productor de azúcar del Caribe, después de Cuba, superando a Jamaica, Barbados y otras islas azucareras. Con las oleadas migratorias, las haciendas productoras se multiplicaron ${ }^{76}$. Según este contexto se puede decir que Fidel llegó a Puerto Rico en un buen momento: fue uno de los emigrantes que debieron beneficiarse de la Cédula de Gracias, además de ser testigo de la transformación que sufría la isla. Sin embargo las cosas no fueron tan sencillas.

Fidel circunstancialmente había nacido en Menorca. Desde las islas Baleares fueron numerosos los emigrantes que se trasladaron a Puerto Rico ${ }^{77}$. Estela Cifré, en su estudio sobre los residentes en dicha isla en el siglo XIX procedentes del litoral mediterráneo español, lo ubica al mismo tiempo en el grupo de baleáricos y en el de catalanes, exponiendo las matizaciones oportunas. Según Cifré, los emigrantes originarios de Baleares fueron 1.037 y los de Cataluña 3.340 ${ }^{78}$.

74. Sobre la cuestión del esclavismo: Hernández Ruigómez, A., "La abolición de la esclavitud en Puerto Rico: Introducción al estudio de las mentalidades anti-esclavistas", en Quinto Centenario. Universidad Complutense, Madrid, 1988, n 14, pp. 27-41. Díaz Soler, L. M., Historia de la esclavitud negra en Puerto Rico, San Juan, 2000, pp. 130-141. Altieri, G. A. C., "Derecho y esclavitud en el Puerto Rico del siglo XIX". inter.c.a.mbio, año 6, n. 7 (2009), pp. 91-127.

75. Navarro García, J. R., Control Social y Actitudes Políticas en Puerto Rico: 18231837. Sevilla, Diputación de Sevilla, 1991, pp. 17-19. Scarano, F. A., Puerto Rico. Cinco siglos de historia. Santa Fe de Bogotá, McGraw-Hill, 1993, pp. 384-385. Lavallé, B., Naranjo, C., Santamaría, A., La América Española (1763-1898), pp. 209-212.

76. Scarano, F.A., Puerto Rico, p. 396.

77. Lavallé, B., Naranjo, C., Santamaría, A., La América Española (1763-1898), p. 215. La aportación más importante de inmigrantes procedía de España: Cataluña, Baleares, Galicia, Asturias y Canarias. También había franceses, corsos, alemanes, ingleses y colonos procedentes de otras colonias americanas.

78. Cifré de Loubriel, E., La formación del pueblo puertorriqueño. La contribución de los catalanes, baleáricos y valencianos. San Juan, Instituto de Cultura Puertorriqueña, 1975, pp. $26,27,188$ y 356. 
Resulta arriesgado ofrecer datos concretos del proceso migratorio, entre otras cosas por la dificultad que entraña la presencia de la emigración clandestina. Durante el siglo XVIII, aunque Andalucía conservaba un lugar de privilegio, aumentó la incorporación de vascos, cántabros, asturianos, gallegos y, en menor número, de catalanes. La presencia catalana, se acentuó durante el último tercio del siglo XVIII y primeras décadas del XIX. Los contingentes estaban formados por funcionarios de la administración, ingenieros militares, religiosos, militares, artesanos (constructores, horneros, zapateros, carpinteros), comerciantes, así como representantes de oficios marineros. Carlos Martínez Shaw la califica de migración tardía, gradual, marítima y mercantil; este aspecto comercial fue el que dio importancia a dicho proceso ${ }^{79}$. En esta línea, Magnus Mörner explicaba este incremento por la creciente importancia demográfica y económica de Cataluña y Valencia, que se produciría más bien por las expectativas generadas por el nuevo continente que por una situación de crisis ${ }^{80}$.

Rosario Márquez, para el período comprendido entre 1765 y 1824 -sin olvidar la realidad de los ilegales-, sitúa el número total de emigrantes peninsulares en 17.231, cifra que obtiene a partir de las licencias solicitadas en la Casa de la Contratación. Un 85\% eran varones, y de ellos el $80 \%$ estaban solteros. En el grupo de mujeres, casi el $51 \%$ estaban casadas, el $43 \%$ eran solteras y el $6 \%$ viudas. Apenas un $40 \%$ de los emigrantes indicaba su origen: entre ellos contabiliza 999 de origen catalán, un 15\% del total peninsular. Con estos porcentajes Cataluña se situaría detrás del País Vasco, Navarra y Asturias. De los catalanes solo una cuarta parte indicó su profesión, siendo la mayoría comerciantes (41\%) y criados (38\%). Relacionando estos oficios con el lugar de destino, vemos que los primeros decidieron preferentemente viajar a las Antillas y los segundos a América Central ${ }^{81}$.

La liberalización de los mercados, a raíz de los Decretos de Libre Comercio, justificaría el desplazamiento catalán. Entre 1765 y 1820, el 98\% de los casos documentados por Josep M. Delgado, correspondería a sectores relacionados con la actividad comercial, aunque fuera en establecimientos modestos. El 43\% de los emigrantes se situarían en el Caribe: Puerto Rico, con 258 inmigrantes documentados, 20,4\% del total, constituía la colonia más numerosa. Con respecto a su procedencia, el 75\% tendría su origen en Barcelona, Vilanova i la

79. Martínez Shaw, C., Cataluña en la carrera de Indias, Barcelona: Crítica, 1981, p. 137 y ss. También en La emigración española a América (1492-1824). Colombres, Asturias, Archivo de Indianos, 1993, pp. 179, 221-224 y "L'emigració catalana a Amèrica (1493-1824). Un balanç provisional", en III Jornades d'Estudis Catalano-Americans. Barcelona, 1992, pp. 15-22. Yáñez Gallardo, C., "L'emigració catalana a Amèrica entre 1830 i 1930", en III Jornades d'Estudis Catalano-Americans. Barcelona, 1992, pp. 279-302.

80. Mörner, M., "La emigración española al Nuevo Mundo antes de 1810. Un informe del estado de la investigación". Anuario de Estudios Americanos, t. XXXII (1975), pp. 43-131.

81. Márquez Macías, R., La emigración española a América (1765-1824). Servicio de Publicaciones Universidad de Oviedo, 1995, pp. 128-151, 161, 206 y 239-246. 
Geltrú, Sitges, Mataró y Tossa ${ }^{82}$. Jordi Maluquer, para 1860, ofrece un total de 2.054 catalanes desplazados y de 1.296, para 1861; Cuba, sobre todo, y su área de influencia fue la zona preferida ${ }^{83}$.

Si nos atenemos al Corregimiento de Tarragona, las localidades con mayor aportación de emigrantes a Puerto Rico fueron las más pobladas y las situadas cerca de la costa: Reus, Torredembarra, Altafulla, Tarragona, La Selva del Camp, Valls y Riudoms. Por otra parte, cuando estos emigrantes Ilegaron a Puerto Rico escogieron localidades como San Juan, Ponce o Mayagüez, de características parecidas a las de partida ${ }^{84}$.

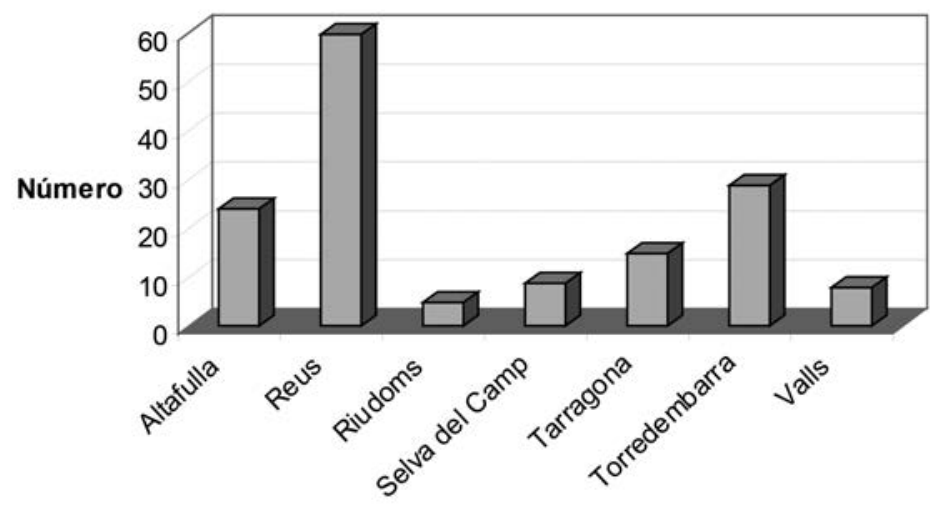

\section{Localidades}

GráfICO. Número de emigrantes a Puerto Rico según localidades de origen ${ }^{85}$. Fuente: Estela Cifré de Loubriel.

Cuando Fidel Gatell Ilegó a Mayagüez ${ }^{86}$ se trasladó a la hacienda de María Dolores Cebollero, que lo recibió como si se tratara de un miembro más de la familia. La casa era amplia y cómoda y la heredad tan extensa que en el último

82. Delgado Ribas, J. M., "La emigración española a América Latina durante la época del comercio libre (1765-1820). El ejemplo catalán". Boletín Americanista, 32 (1982), pp.115-137.

83. Maluquer de Motes, J., "L'emigració catalana a Amèrica durant la primera meitat del segle XIX. Una valoració global", en III Jornades d'Estudis Catalano-Americans. Barcelona, 1992, pp. 161-170.

84. Cifré de Loubriel, E. La formación del pueblo puertorriqueño... pp. 24, 35 y 36 . Ensenyat Julià, J., Mallorquins a Puerto Rico. Palma, Col-lecció Balears i Amèrica, 13, 1992, p. 24.

85. A pesar que Estela Cifré cita todas las poblaciones de procedencia de los emigrantes, en la gráfica solamente se incluyen las más significativas.

86. "Mayagüez". Enciclopedia de Puerto Rico, Consultado el 19/06/2016 en: http://www.en ciclopediapr.org. Mayagüez, situada en la costa oeste de Puerto Rico, en una zona plana, es muy fértil; su suelo era muy adecuado para cultivar caña de azúcar, café, cacao, tabaco, algodón, arroz y maíz. En 1836 recibió el título de Villa, que le permitió tener Cabildo. El desarrollo alcanzado hizo que mediado el siglo XIX dispusiera de aduana, ayuntamiento, cuartel, hospital militar y cárcel. 
año había producido una renta de 45.000 pesos y precisaba del trabajo de 135 negros, sin contar las criadas y los esclavos destinados al servicio de la casa. Para transportar la caña de azúcar disponían de 82 ayuntas ${ }^{87}$, que tiraban de veinte carros, y de dos molinos para molerla, además de las fábricas con sus alambiques y almacenes ${ }^{88}$.

Fidel comentaba que los hacendados disfrutaban de su propia montura y criado. La diversión parecía ser el único objetivo de los miembros de esta sociedad. Al llegar a la finca, le ofrecieron inmediatamente una hamaca y a continuación le encendieron un tabaco: fumar era tan usual que hasta las mujeres lo hacían. En las cartas que Fidel remitió queda reflejado el buen trato que le dispensaba la señora Cebollero ${ }^{89}$.

En Barcelona residía Pedro Jerónimo Goicovich, hijo de María Dolores Cebollero y de su esposo Genaro, que había cursado estudios de medicina en la Sorbona. Goicovich, independientemente de su actividad profesional, pudo mantener relaciones comerciales con la familia Moragas y otros comerciantes: podemos asegurar que en algún momento sirvió de enlace entre Magí y Fidel Gatell para intercambiar correspondencia. La relación entre Goicovich y Magí era reciente, según lo manifiesta el puertorriqueño al pedirle cierta suma que precisaba con urgencia, ya que unas gestiones con la Compañía de Joaquim Rius no habían prosperado y se encontraba en una situación comprometida. Magí Gatell lamentaba no poder ayudarle personalmente, pues la cantidad de 1.000 duros excedía a sus posibilidades, lo que justificaba por el gasto que había significado el viaje de Fidel a tierras americanas y porque la economía del territorio no lo permitía:

[...] siento vivamente el no poder dar autorización de proporcionarle los 1.000 duros que a V. le convienen, haciendo el sacrificio del 2 o 3 por ciento mensual; este es un pueblo que se vive de propiedad, que a tenor del precio de los frutos y en particular de vino abandonado, apenas sufragan los gastos, a más no hay ninguna casa acaudalada para desembolsar esta suma $[\ldots]^{90}$.

87. DLE. Yunta. Par de bueyes, mulas u otros animales que sirven en la labor del campo o en los acarreos.

88. IMR. Carta de Fidel Gatell Moragas a Magí Gatell, Mayagüez, 8 de abril de 1835.

89. IMR. Carta de Fidel Gatell Moragas a Magí Gatell, Mayagüez, 8 de abril de 1835.

Instituto Dominicano de Genealogía. Según Jail Lenín Aurich Martínez, miembro de este centro, Dolores Cebollero era de origen aragonés y se casó con Genaro Goicovich, con quién tuvo nueve hijos. Su familia formaba parte del sector más relevante de Puerto Rico. Consultado el 07/05/2016 en: http://www.idg.org.do/capsulas/diciembre2007/diciembre200715. htm.

90. IMR. Cartas de Pedro Gerónimo Goicovich a Magí Gatell, Barcelona, del 13, 16 y 24 de febrero de 1835 . 
Fidel Gatell, ocho días después de su llegada, había recibido dos ofertas de trabajo. La primera en una hacienda con plantaciones de café, y la segunda en una casa de comercio de la Guadilla [Aguadilla], situada a unas cuatro horas de Mayagüez ${ }^{91}$. Después de atender los consejos de "personas de bien" aceptó la segunda propuesta, de D. Juan Basora y Compañía, que además tenía buenas relaciones con los señores Flaquer, quienes también facilitaron el intercambio epistolar con su familia de Torredembarra. Otra circunstancia que aconsejaba esta decisión era que su jefe inmediato era mallorquín y su esposa mahonesa como él-, lo cual favorecía la relación ${ }^{92}$.

En Mayagüez residía una numerosa comunidad catalana, con gran influencia. En 1830, los Basora poseían dos negocios en Mayagüez: Basora y Compañía y Basora Hermanos ${ }^{93}$. La población francesa también arraigó desde comienzos del siglo XIX, hasta el punto de que, cuando comenzó la guerra de la Independencia y el gobierno peninsular decidió expulsarles y expropiar sus bienes, la población local les apoyó, y no sólo no se fueron, sino que aún aumentaron su presencia ${ }^{94}$.

La compañía de Joan Basora, por la actividad comercial, era de las más importantes: disponía de una tienda con diversos almacenes distribuidos por la isla, que era preciso proveer. A Fidel le ofrecían un sueldo de 25 dólares al mes, comida, tabaco, ropa limpia y asistencia médica aparte. Su ocupación consistía en adquirir azúcar, café, tabaco y otros productos. Cuando llegaba la época de la cosecha salía con su montura para negociar las compras. Con cierta frecuencia viajaba a la cercana isla danesa de Saint Thomas, lugar de intercambio de productos manufacturados. El hecho de tener que embarcar no le complacía, sobre todo después de la desagradable experiencia sufrida durante el trayecto por el Atlántico, pero formaba parte de sus obligaciones laborales y quizás le ayudaría a anudar contactos para poder establecerse por su cuenta. Los viajes a la isla estaban recompensados con un sobresueldo, que variaba en función de la tarea realizada ${ }^{95}$.

91. Rivera Ruiz, A. M., Aguadilla el pueblo que dio la espalda al mar. San Juan, Editorial Isla Negra, 2007, pp. 21-34. Aguadilla es una localidad de la costa nordeste de Puerto Rico; el fácil acceso a la costa y por estar resguardada del viento permitía la llegada de navíos de gran calado. Hasta el último cuarto del siglo XVIII había dependido de Aguada. La agricultura y el comercio eran las principales fuentes de riqueza; la pasividad de las autoridades españolas para aprovisionarla potenció el contrabando.

92. IMR. En la carta que envía a su padre, Fidel, cuando se refiere a la esposa de su jefe nacida en Mahón, la denomina paysana.

93. Sonesson, B., La Emigración de Carranza a Puerto Rico en el siglo XIX: (Mercadeo y capital indiano). Sevilla, CSIC. Consejo de estudios hispano-americanos, 2003, p. 50.

94. Camuñas Madera, R. R., "Los franceses en el oeste de Puerto Rico". Caravelle, 53 (1989), pp. 25-36.

95. IMR. Carta de Fidel Gatell a Francesc Gatell. Aguadilla, 12 de mayo de 1835. 
Para Fidel, era el primer paso para adquirir experiencia en una tierra extraña $y$, en un futuro no muy lejano, poder hacer fortuna. Poco tardaría en darse cuenta de que la época en que se ganaba dinero rápidamente ya había pasado y que se acercaban tiempos difíciles. En la carta que, a mediados de mayo, dirigía a su hermano así lo manifestaba:

[...] esto está malo para ganar dinero así como conozco que algunos años atrás tenia de ser muy facil el adquirirlo nada mejor prueva esto, que conocer los sujetos que en aquel tiempo lo adquirieron [...] Pero estamos ya aqui y espresito aprovecharé el viaje ${ }^{96}$.

Pese a todo, consideraba que -en comparación con Cataluña-, para aqueIlos que deseaban trabajar, aún era una tierra de oportunidades, y el hecho de haber iniciado esta aventura no lo estimaba como tiempo perdido. Sin concretar nacionalidades señalaba la presencia en la isla de un importante núcleo de inmigrantes extranjeros. En esta misma carta -en la postdata-, pedía información sobre lo que sucedía en la Península, concretamente en relación a Zumalacárregui. El sentir y el deseo que tenían los españoles residentes en Puerto Rico era el reconocimiento de la independencia de: "[...] las Américas pues que a todos nos conviene muchísimo [...]"97. Fidel Gatell, probablemente, responsabilizaba a la metrópoli de la ralentización que experimentó la agricultura portorriqueña en esta época, en la que insistiremos más adelante ${ }^{98}$.

Fidel Gatell había abandonado España en un momento políticamente delicado. Como es sabido, el fallecimiento de Fernando VII, en setiembre de 1833, significó la regencia de la reina viuda María Cristina, tutelando el reinado de su hija Isabel II. Las pretensiones del hermano del rey, Carlos María Isidro, dieron paso a la guerra civil: las guerras carlistas. En relación a Tomás de Zumalacárregui -por el que se interesaba Gatell-, como es conocido, moriría de un disparo en el sitio de Bilbao de 1835.

A mediados de setiembre de 1835 se dirigía a su familia materna. Como novedad le informaba de una nueva ocupación, pues gracias a la señora Cebollero había formado una compañía de comercio con Jorge, uno de sus hijos: la empresa se denominaría Fidel Gatell y Cía y se ubicaba en Añasco. Fidel Gatell manifestaba con sorpresa que, a pesar de que la desproporción de capitales aportados era muy grande, en el contrato se acordó que los beneficios se repartirían a partes iguales. Dolores Cebollero avalaba la iniciativa con su hacienda, valorada en 200.000 pesos. Fidel confesaba trabajar día y noche sin descanso, y con el aprecio que le profesaban sus colegas comerciantes esperaba prosperar en poco tiempo, sobre todo porque apenas tenía gastos,

96. IMR. Carta de Fidel Gatell a Francesc Gatell. Aguadilla, 12 de mayo de 1835.

97. IMR. Carta de Fidel Gatell a Francesc Gatell. Aguadilla, 12 de mayo de 1835.

98. Santamaría García, A., "Azúcar, economía y reformas coloniales. Puerto Rico y Cuba, 1765-1840". Coloquios de Historia Canario-Americana 1976-2006 (2008), pp. 1619-1636. 
no debía pagar el alquiler de cuatro almacenes, ni tampoco su manutención. Añadía que, para que no se sintiera inferior al resto de la familia, le habían comprado un caballo ${ }^{99}$.

Fidel Gatell explicaba también que en la isla estaba a punto de finalizar el período más lluvioso; los campesinos de su compañía estaban recolectando arroz y café, artículos con los que esperaba obtener importantes beneficios, aunque aquel año la producción no había sido buena; un temporal, que levantó casas enteras y hundió numerosos barcos, la dañó ${ }^{100}$; Fidel se felicitaba de no haber tenido ningún percance, porque cuatro días antes de la llegada del huracán se encontraba en la isla de Saint Thomas ${ }^{101}$.

Siguiendo con el relato epistolar, refiere que desde Barcelona le habían llegado noticias del incendio de los conventos la noche del 25 de julio, y preguntaba a sus familiares si los hechos también habían ocurrido en Valls ${ }^{102}$, expresando el deseo de poseer fortuna para contribuir a la reconstrucción de los edificios religiosos. Finalmente, aprovechaba la misiva para reclamar a su abuela que no olvidara enviarle pasas, higos, nueces y avellanas para obsequiar a Dolores Cebollero. Él le correspondería con cigarros, pero los remitiría más adelante, porque los que ahora tenía no eran de buena calidad ${ }^{103}$. Esta es la última carta que disponemos de Fidel. Por la correspondencia hemos conocido que en 1835 había trasladado su residencia de Aguadilla a Añasco ${ }^{104}$, situada justamente entre Mayagüez y Aguadilla, pero después le perdemos la pista. Hasta el año 1843 se produce un vacío documental de ocho años. Será la Gaceta de Puerto Rico de febrero de 1844 la que nos informe de que en 1843 había sido elegido re-

99. AHT. Fons de la família Moragas (1413-1951). Correspondència familiar, 1823-1835. Carta de Fidel Gatell Moragas a Rosa Moragas Dot, Añasco, 12 de setiembre de 1835.

100. Navarro García, J. R., "Puerto Rico, 1808-1837. De la fidelidad al conflicto". Memorias. Revista Digital de Historia y Arqueología desde el Caribe, no. 19 (enero-abril 2013), pp. 44-68. Consultado el 12/06/2016 en: http://www.scielo.org.co/pdf/memor/n19/ n19a04.pdf.

Se refiere al huracán San Hipólito, que el 13 de agosto atravesó la isla, afectando principalmente la parte este y norte. Estas tormentas, muy frecuentes en el Caribe, dejaban las cosechas muy maltrechas, hasta el punto de poner en peligro la economía de las haciendas. La pérdida de productos destinados al consumo interior producía un importante incremento de enfermedades y de mortalidad entre la población más necesitada.

101. AHT. Fons de la família Moragas (1413-1951). Correspondencia familiar, 1823-1835. Carta de Fidel Gatell Moragas a Rosa Moragas Dot, Añasco, 12 de setiembre de 1835.

102. Portet Pujol, J., "L'exclaustració de religiosos de l'any 1835". Ausa, XXI, 151 (2003), pp. 29-49.

103. AHT. Fons de la família Moragas (1413-1951). Correspondència familiar, 1823-1835. Carta de Fidel Gatell Moragas a Rosa Moragas Dot, Añasco, 12 de setiembre de 1835.

104. "Añasco". Enciclopedia de Puerto Rico, Consultado el 19/06/2016 en: http://www. enciclopediapr.org. Fundada en el primer tercio del siglo XVIII, se encuentra situada en los valles de la costa oeste, cerca del río Grande de Añasco, entre Aguadilla y Mayagüez; en un terreno fundamentalmente llano; en 1813 disponía de aduana. 
gidor de Añasco ${ }^{105}$; siendo alcalde segundo Demetrio Goicovich, seguramente hijo de Dolores Cebollero.

Las noticias vuelven a aflorar un año más tarde. Se trata de la descripción de una propiedad que poseía en 1845, sembrada con frutos menores. Teniendo en cuenta que Fidel Gatell permaneció en Añasco durante diez años, bien pudiera estar relacionada con la compañía que regentaba junto a Jorge Goicovich. La finca tenía una superficie de 100 cuerdas $^{106}, 12$ de las cuales estaban dedicadas al cultivo de caña, mientras en tres había café y en otras diversos frutos. La caña de azúcar era el producto de mayor valor comercial. También era propietario de ocho bueyes, que constituían la fuerza de trabajo, doce vacas y nueve caballos. El terreno estaba valorado en 3.000 pesos, los edificios en 1.000, los cultivos en 800 y los esclavos en $1.680^{107}$.

Este mismo año sería nombrado alcalde de la localidad. Al año siguiente, Rafael Arístegui y Vélez de Guevara, conde de Mirasol ${ }^{108}$, gobernador de Puerto Rico, lo designó Teniente a Guerra del partido de Añasco. Por Real Decreto de 27 de febrero de 1846, la Monarquía ordenó recuperar este cargo en Puerto Rico, en sustitución de los ayuntamientos, con la misma autoridad que tenían en 1836. El Real Decreto de 23 de julio de 1835, expedido provisionalmente para organizar a los Ayuntamientos, no proporcionó los resultados previstos; al contrario, originó más gastos y dificultades a la administración. Mientras no se redactara una ley especial para los municipios de Ultramar, en Puerto Rico, sólo tendrían ayuntamiento San Juan, Mayagüez, Arecibo, Humacao, Ponce, Aguadilla, Guayama y San Germán. La autoridad en los restantes pueblos residiría en un Teniente a Guerra ${ }^{109}$.

105. Gaceta del Gobierno de Puerto-Rico, núm. 23, Jueves, 22 de febrero de 1844, p. 4. Consultado el 07/05/2016 en: http://ufdc.ufl.edu/AA00023800/00918/3x.

106. DLE. Cuerda: En Puerto Rico, medida de superficie equivalente a 3.929 centiáreas.

107. Purcell Gatell, W. M., La familia Gatell en Puerto Rico: Un recorrido histórico. Manuscrito inédito. Archivo General de Puerto Rico (AGPR). Fondo de Gobernadores Españoles. En 1853 Fidel Gatell disponía de otra finca en el barrio de Corcovada, también en Añasco, valorada en 4.000 pesos y 260 reales. Scarano, F. A. Puerto Rico, p. 398. Los bueyes eran la fuerza de trabajo; según Francisco Scarano, en esta época, las fincas se denominaban haciendas de bueyes, porque para mover las muelas utilizaban estos animales; la alternativa fueron los molinos de viento, haciendas de viento, y más adelante la máquina de vapor, haciendas de vapor.

108. Archivo Histórico Nacional (AHN). Ultramar, legajo 1093, Exp. 24. Rafael de Arístegui, entre otras distinciones, estaba en posesión de la Gran Cruz de Carlos III, Gran Cruz de San Hermenegildo, la de Isabel la Católica, caballero de la Orden de San Luís de Francia y de cuarta clase de la de San Fernando. Era teniente general, senador, capitán general, presidente de la Real Audiencia de Puerto Rico, miembro de la Sociedad Económica de Jerez de la Frontera y vice-protector de la de Puerto Rico.

109. Real Decreto de 27 de febrero de 1846, que organiza el régimen municipal de la isla de Puerto-Rico, y directorio formado para su cumplimiento y efectos sucesivos por disposición del Sr. Conde de Mirasol, gobernador y capitán general de la misma. Puerto-Rico, Imprenta 
Las atribuciones de los Tenientes a Guerra, por lo que se refiere a cuestiones políticas y judiciales, según expresaba el artículo 36 del expresado decreto de 1846, eran iguales a las de los Alcaldes. La duración del servicio era de un año y la remuneración correspondía a los aranceles por juicios de paz y verbales. Una junta formada por cuatro vecinos contribuyentes -dos comerciantes y dos agricultores- nombrados por el gobierno, además del comandante militar, el rector, el capitán del puerto, el administrador de rentas o el de la aduana y el Procurador Síndico, asesoraba a los tenientes ${ }^{110}$.

Eran responsables de la seguridad: formación de las compañías de milicias urbanas, vigilancia de la cárcel y la costa, para evitar la huida de esclavos y la práctica del contrabando, y traslado de los prisioneros a la capital. También se ocupaban de cuestiones administrativas y judiciales: enviar las órdenes oficiales, percibir los derechos sobre la tierra, cobrar el salario del capellán e intervenir como jueces y escribanos ${ }^{111}$.

El 14 de diciembre de 1847, Fidel Gatell también fue nombrado Sargento Mayor de milicias urbanas de Añasco, cargo que ocuparía hasta mediados de $1850^{112}$. Este mismo año, Rafael Arístegui le había encomendado la redacción de un informe urbanístico, económico y social de dicha localidad. En él Fidel Gatell describía Añasco como un pueblo:

[...] que contenía 2 casas de mampostería; 118 casas de madera y tejas; 104 bohíos con yaguas; 1 casa del rey de madera y tejas; otra igual del cuerpo de guardia y cárcel y la iglesia en mampostería en medio de la plaza [...] las tierras de este partido son de la más excelente calidad, en particular las bajas, cuyas frondosas vegas de espontáneas muy pingues cosechas de frutos y de granos. La caña se cultiva con utilidad conocida, y lo propio el café, siendo de bastante importancia el arroz que se produce en años regulares, y la cual cosecha en lo antiguo antes de estar ocupados los mejores terrenos de ciénagas con la caña era de muchísima consideración; debido también á que en éste son constantes las Iluvias. La crianza de toda clase de ganado es insignificante en el partido, pues solo tienen los dueños de haciendas y estancias lo que necesitan para los trabajos [...] Hay 19 haciendas y dos partes de otras en dicho fruto ubicados en la Villa de Mayagüez, limítrofes con éste; 33

del Gobierno, 1846. En relación a la organización municipal establecida por el Real Decreto de 1835 ver Navarro García, J. R., Control Social, pp. 291-297.

110. Directorio para la ejecución del decreto de 27 de febrero de 1846, publicado en 1770, corregido en 1816 y que rigió hasta 1836. Puerto-Rico, mayo de 1846. El Conde de Mirasol.

111. Abbad y Lasierra, I. Fray, Historia Geográfica, Civil y Natural de la Isla de San Juan Bautista de Puerto-Rico. Puerto-Rico, Imprenta y Librería de Acosta, 1866, p. 257.

112. AHN. Ultramar, legajo 1093, Exp. 24. Nombramientos de Fidel Gatell Moragas como Teniente á Guerra y Sargento Mayor de milicias de Añasco. 
cafetales y 802 pequeñas estancias, que también producen algún café y frutos menores [...] En 1847, La población total del partido, se compone de 11.714 habitantes con a saber; de estos 1.185 reunidos en la población, siendo 839 blancos, 100 mulatos libres, 11 negros libres, 114 mulatos esclavos, 121 negros esclavos. En los barrios de campo ecsisten 10.529, siendo 7.573 blancos, 1.893 mulatos libres, 39 negros libres, 276 mulatos esclavos y 748 negros esclavos [... $]^{113}$.

A finales de 1847, Juan Prim ${ }^{114}$ fue designado gobernador de Puerto Rico, sustituyendo al conde de Mirasol; este nombramiento era una forma de tenerle lejos de las continuas conspiraciones. El momento en que se produjo el relevo gubernamental fue una época especialmente difícil. A finales de la década de 1830, la expansión agraria portorriqueña se había ralentizado y el azúcar se vio especialmente afectado. Las medidas proteccionistas, que recayeron sobre los productos extranjeros, con el aumento de tasas, provocaron la reacción de los Estados Unidos -Guerra de las Harinas-, perjudicando la producción de azúcar, café y tabaco ${ }^{115}$. Los precios del azúcar descendieron a su nivel más bajo en medio siglo, mientras que el resto de la producción agraria no compensó el estancamiento azucarero. Una sequía prolongada provocó episodios de hambre, incidiendo especialmente en la población más pobre. Además, hay que añadir los motines de esclavos en algunas islas cercanas -Martinica, Guadalupe-, que causaron gran preocupación entre las élites y las autoridades de la isla ${ }^{116}$. Entre 1838 y 1848 había aumentado la presión inglesa contra el trá-

113. Reconocimiento General del Casco Urbano tradicional Añasco, Puerto Rico. Informe Final. Municipio de Añasco, Septiembre, 2007, pp. 21-23. [Consultado el 07/05/2016] en: http://www2.pr.gov/oech/oech/Documents/Inventarios/Inventario\%20General\%20de\%20 la\%20Zona\%20Hist\%C3\%B3rica\%20de\%20A\%C3\%B1asco.pdf.

114. Juan Prim y Prats (1814-1870) fue un militar y político español que accedió al ejército, defendiendo la causa de Isabel II frente a su tío Carlos María Isidro, durante las guerras carlistas. Compatibilizó su actividad castrense con la política, siendo elegido diputado en diversas ocasiones. Después de su gestión como gobernador de Puerto Rico tuvo una destacada participación en la guerra de África (1859-1860). Finalizado este conflicto regresó a América, concretamente a México, al mando de un combinado hispano-franco-británico. Manifiestamente liberal participó activamente en la Revolución de 1868, que supuso el exilio de la reina. En el gobierno que se constituyó posteriormente fue ministro de la Guerra y presidente del Consejo de Ministros. Fue uno de los principales avaladores para restaurar la monarquía en la persona de Amadeo de Saboya; coincidiendo con la llegada del nuevo soberano Prim fue asesinado.

115. Sobre estas cuestiones: Díaz Soler, L. M., Puerto Rico. Desde sus orígenes hasta el cese de la dominación española. Río Piedras: Universidad de Puerto Rico, 1994, p. 501. Diego, E. de, "Puerto Rico: el fracaso de un modelo esclavista atípico". Quinto Centenario, 10, (1986) pp. 155-182. Lavallé, B., Naranjo, C., Santamaría, A., La América Española (1763-1898), pp. 233 y 234.

116. Scarano, F. A., Puerto Rico, p. 415. Santamaría García, A., "Economía, 1800-1898", en González, L. E., Luque, M. D. (eds.); Naranjo Orovio, C. (dir.). Historia de Puerto Rico. Madrid, Ediciones Doce Calles, 2012, pp. 135-167. 
fico de esclavos, sobre todo después de la llegada del primer cónsul británico, John Lindegren. En el período entre 1845 y 1847, a pesar de que se buscaban argumentos para mantenerlo, dicho comercio empezó a decaer. Las autoridades temían que se reprodujeran los motines de Haití. Puerto Rico tendría unos 500.000 habitantes, y un $10 \%$ eran esclavos ${ }^{117}$.

Prim desembarcó el 15 de diciembre de 1847. Desde el primer momento tuvo que hacer frente a la inestabilidad provocada por el bandolerismo. A finales de febrero del año siguiente se dispuso a inspeccionar la isla; el regreso a San Juan se produjo a mediados de mayo. Conocida la situación, impuso su férrea autoridad castrense ${ }^{118}$. Estaba dispuesto a mantener el dominio español a cualquier precio. El 31 de mayo puso en vigor el Código Negro, un severo reglamento que determinaba la aplicación de Consejo de Guerra a las personas de raza africana, independientemente de que fueran esclavos o libres, que cometieran cualquier delito; el tomar armas podía significar su fusilamiento ${ }^{119}$.

La gestión de Prim al frente del gobierno de la isla fue muy discutida. Su plan para recuperar Santo Domingo fue desestimado por las autoridades españolas. La relación con la Real Audiencia insular, a consecuencia de la publicación del Código Negro y posterior represión, no fue nada fluida, porque el gobernador limitaba la autoridad del tribunal. La opinión que les merecía a los cónsules inglés y francés no era en absoluto favorable. La situación precisaba una administración con mayor tacto diplomático, por lo que en julio de 1848 Isabel II nombró a Juan de la Pezuela para sustituir a Prim ${ }^{120}$.

Fidel Gatell, como teniente a guerra, debió coincidir con el militar reusense. En una carta de 9 de octubre de 1850 decía a su tío Fidel Moragas:

Ya V. estarà al corriente de cuanto ocurrió en la Ysla de Cuba, maxime estando allí su hijo ${ }^{121}$. Parece que los vecinos Norte americanos nos quieren mucho pues no pierden ocasión de darnos pruebas. Muy satisfechos estamos, al ver el interés que se va tomando el Gobierno para sostener estas Antillas; bien puede hacerlo pues que no deja de haber enemigos dentro y fuera de ellas. Aquí se asegura que pronto volveremos a tener al paysano Prim de gobernador. Conmigo se llevó muy bien y en

117. Morales Carrión, A., "El año 1848 en Puerto Rico: aspectos del mando de Prim". Revista de Occidente, núm. 147 (junio 1975), pp. 211-242.

118. Olivar Bertran, R., Prim. Madrid: Ediciones Giner, 1975, pp. 102-115.

119. Negroni, H. A., Historia militar de Puerto Rico. Madrid, Ediciones Siruela, 1992, p. 286. Morales Carrión, A., "El año 1848 en Puerto Rico, pp. 211-242. Gaceta del Gobierno de Puerto Rico, núm. 67, 3 de junio de 1848.

120. Morales Carrión, A., "El año 1848 en Puerto Rico, pp. 211-242.

121. Los Moragas tenían un establecimiento comercial en esta isla. 
las varias veces que comí con él siempre me distinguió poniendome a su lado ${ }^{122}$.

Sin saber hasta qué punto pudo influir en ello su relación con Prim, cuando estalló la guerra de África, como muchos funcionarios, Fidel colaboró en los donativos destinados a ayudar a los combatientes españoles; su aportación consistió en 121 pesos y 26 céntimos ${ }^{123}$.

Con respecto a su vida íntima, Fidel se casó dos veces. De su primera esposa sólo conocemos el apellido: López; de este matrimonio nacería una hija, María Elena ${ }^{124}$. Posteriormente, a comienzos de la década de los años cincuenta, contraería nuevas nupcias, con Ana María de los Reyes García de Quevedo, de origen venezolano, aunque nacida en Añón. Sus padres fueron Pedro García de Quevedo Cos de Sasturri y Josefa Droin de la Bourdennaise, pertenecientes a familias acomodadas de Santa Ana de Coro, que Ilegaron a Puerto Rico a raíz de la revolución de Simón Bolívar ${ }^{125}$. Entre sus descendientes destacó José Heriberto García de Quevedo ${ }^{126}$.

Del matrimonio entre Fidel Gatell y Ana García de Quevedo nacieron por lo menos seis hijos y dos hijas. Siguiendo el orden cronológico fueron: José María, Pedro Tomás, Carmen, Federico, Francisco, Rafael, Ana Rita y Manuel Ricardo. Los tres primeros vieron la luz en Añasco, mientras que los demás lo hicieron en Ponce, punto de destino de Fidel al ocupar un empleo en la administración, como enseguida veremos ${ }^{127}$.

Ponce está situada en la parte meridional de Puerto Rico. A principios del siglo XIX su economía se asentaba en la ganadería y en el cultivo del café; a partir de las reformas de 1815 se produjo un cambio y la caña adquirió mayor protagonismo. Después de la revolución haitiana, Estados Unidos fue el princi-

122. Olivé Serret, E., Els Moragas. Història íntima, p. 28.

123. Gaceta de Puerto-Rico, jueves 19 de enero de 1860, núm. 8.

124. Disponemos de los datos biográficos de los hijos de Fidel Gatell gracias a documentos del Archivo Histórico Nacional y por la recopilación realizada por las familias Gatell Toro y Purcell Gatell, la mayor parte de los cuales, siguen residiendo en Puerto Rico. Waldemar Purcell Gatell, en 2015 terminó de elaborar un manuscrito inédito: La familia Gatell en Puerto Rico: Un recorrido histórico, cuyo contenido se ha redactado a partir de datos procedentes de archivos puertorriqueños, documentación familiar y prensa.

125. Arcaya, P. M., Población de origen europeo de Coro en la Época Colonial. Caracas, Academia Nacional de la Historia, 1972. p. 205.

126. Amores, M., "García de Quevedo, José Heriberto". Grupo de Investigación del Cuento Español del Siglo XIX (GICES XIX). Universitat Autònoma de Barcelona. [Consultado el 23/06/2016] en: http://gicesxix.uab.es/showAutor.php?idA=267 José Heriberto García fue un conocido escritor y poeta, militar y diplomático, que hacia 1847 se encontraba en España colaborando en diversos periódicos, como El Espectador, Semanario Pintoresco Español, La Época y El León Español, o siendo director de EI Siglo XIX.

127. Purcell Gatell, W. M., La familia Gatell en Puerto Rico. José María, Federico y Ricardo estuvieron vinculados a la Masonería. José María, Ilegó a ser Venerable Maestro de la Logia Masónica Hijos de la Luz. 
pal importador de azúcar, tanto de Puerto Rico como de Cuba ${ }^{128}$. A mediados de la centuria las élites de Ponce procedían de familias inmigrantes de primera o segunda generación: el empuje de la producción azucarera hizo que estos nuevos propietarios y los esclavos relegasen a la población tradicional. Entre 1815 y 1845 la economía de Ponce cambió radicalmente. Gracias a unos terrenos fértiles, unas condiciones climáticas óptimas, la relativa proximidad a la colonia de Saint Thomas, a una mayor superficie de la propiedad y a la facilidad en el transporte, la caña de azúcar se convirtió en un monocultivo. En 1845, de las 86 haciendas que controlaban esta producción el 26\% correspondía a portorriqueños, el $21 \%$ a españoles, el $17 \%$ a franceses y el $21 \%$ eran gentes de diversas nacionalidades, mientras que el $15 \%$ restante eran de procedencia desconocida. Con respecto al origen regional de los inmigrantes, en esta fecha, de los 18 hacendados españoles, 12 eran oriundos de Cataluña, igual que la mayoría de las 15 casas de comercio mayorista. Los catalanes poseían sociedades familiares que se alimentaban de contratos privilegiados con financieros y comerciantes, ubicados en Ponce y San Juan o en ciudades de la Península, dentro de un contexto endogámico ${ }^{129}$. Birgit Sonesson destaca, hacia 1840, la importancia de Saint Thomas -puerto franco desde 1764-, dentro de las redes comerciales de los catalanes, los cuales desde la época de la Real Compañía de Barcelona exportaban café y tabaco e importaban manufacturas europeas y norteamericanas, en un marco económico regional. La expansión de la economía y el crecimiento demográfico de Puerto Rico impulsó la demanda de artículos y de provisiones; coyuntura que aprovecharon catalanes y vascos para adquirirlos en Saint Thomas y distribuirlos en Puerto Rico ${ }^{130}$.

A pesar de que a lo largo de la década de 1840 se produciría la citada crisis coyuntural azucarera, éste sería a grandes rasgos el escenario que se encontraría Fidel Gatell cuando el 6 de febrero de 1855 fue designado Vista ${ }^{131}$ de la aduana de Ponce, con un sueldo anual de 1.000 pesos. Sustituía a Miguel Antonio Flores quien, después de más de 32 años de leal servicio, fue cesado, ignorándose las causas.

La diligencia mostrada en el municipio de Añasco y su lealtad al gobierno, reflejada en su hoja de servicios, facilitaron a Fidel el acceso a la plaza de la aduana. Para ocupar este empleo la administración exigía que, en el momento

128. Scarano, F. A., Puerto Rico, pp. 399-400. También en Sonesson, B., "Els catalans a Puerto Rico, 1840-1920", en III Jornades d'Estudis Catalano-Americans. Barcelona, 1992, pp. 221-233.

129. Scarano, F. A., "Inmigración y estructura de clases: Los hacendados de Ponce, 18151845", en Scarano, F. A., (ed.). Inmigración y clases sociales en el Puerto Rico del siglo XIX. Río Piedras: Ediciones Huracán, 1985, pp. 21-66.

130. Sonesson, B., "Els catalans a Puerto Rico, 1840-1920", pp. 221-233. También en: Catalanes en las Antillas. Un estudio de casos. Colombres, Asturias, Archivo de Indianos, 1995, pp. 37-42.

131. DLE, Vista: Empleado de aduana que cuidaba de registrar los productos. 
de tomar posesión, el titular presentase un aval, por si posteriormente era preciso dar cuenta de su actuación. Fidel no disponía de suficiente liquidez y fue José María Labarthe quién hipotecó una finca suya -el Parnaso-, como fianza. Este gesto llevaría no pocos quebraderos de cabeza a la familia de José Emeterio Cabrera, que posteriormente la compró: treinta años después, en 1883 -cuando hacía más de veinte que Fidel había fallecido- la Gaceta de Puerto Rico publicaba un aviso por el que la Contaduría General de la Hacienda Pública de Puerto Rico, a raíz de ciertas irregularidades observadas por el Tribunal de Cuentas del Reino en los balances de la aduana de Ponce de mayo de 1860, de julio a diciembre de 1865, y de enero, febrero y abril de 1866, requería comparecer ante la Contaduría a los representantes o herederos de Gabriel González Zabala y de Fidel Gatell Moragas, administrador y contador de la citada aduana, para aclarar unas anomalías. Mientras este asunto no se resolviera la finca estaba sujeta a $\operatorname{cargas}^{132}$. Finalmente el Ministerio de Hacienda aceptó liberar la hipoteca, a cambio de dos títulos de deuda perpetua, al 4\%, por un importe de 13.000 pesetas. El ingreso se formalizó el 22 de julio de 1891, pero el caso no se cerró hasta que se dictó la Real Orden del 3 de febrero de $1893^{133}$.

El 15 de febrero de 1858, Fidel elevó a la Reina una petición de licencia de seis meses, para trasladarse a España y curarse de una enfermedad, calificada de incurable en aquellas islas, pero de más fácil solución en la Península. El 14 de marzo de 1857 Rafael María Pujals, profesor de medicina y cirugía, había certificado que Fidel padecía disentería aguda crónica. La medicación aplicada no pudo contrarrestar los efectos perniciosos del clima, de modo que con el tiempo se acentuó el aspecto demacrado del enfermo. Tal como regulaba la legislación, los doctores José Moringlane y Jaime Piris, residentes en el distrito, le examinaron, confirmaron el diagnóstico y determinaron que si no se trasladaba a la Península Fidel estaba en grave riesgo. En junio del año siguiente se le concedía la licencia ${ }^{134}$. Dos años antes también había estado en España: una certificación de José Montojo Albizu, capitán del puerto de Cádiz, lo confirma. En su expediente no consta el motivo del viaje $\mathrm{e}^{135}$.

Antes de salir para la Península, el 16 de agosto de 1858, Fidel Gatell fue ascendido a Contador de la Aduana de Ponce, por promoción del anterior fun-

132. Chronicling America: Historic American Newspapers. Lib. of Congress. Gazeta de Puerto-Rico. volume (None), Aviso de la Contaduría general de Hacienda Pública de la Isla de Puerto Rico. Máximo González, Puerto Rico, 20 de abril de 1883.

133. AHN. Ultramar. Legajo 1179, Exp. 26. Recurso de alzada de D. Enrique Cabrera contra una resolución de la Intendencia General de Hacienda de Puerto Rico.

134. AHN. Ultramar. Legajo 1093, Exp. 24. Solicitud de licencia a la Reina y certificación de Rafael Pujals.

135. AHN. Ultramar. Legajo 1093, Exp. 24. Certificado de embarque, Cádiz, 7 de marzo de 1855. 
cionario Juan García Jové: el puesto significaba percibir un sueldo de 1.500 pesos anuales. Por entonces tenía 51 años ${ }^{136}$.

Desconocemos cuando regresó. Retomamos el hilo de su carrera cuando el 27 de noviembre de 1870 fue designado para ocupar la plaza de Oficial Primero de la Contaduría Central de Hacienda; el destino representaba un salario de 3.500 pesetas y 4.500 de sobresueldo. En ese momento se encontraba de nuevo en España, pues el día 30 había embarcado en Cádiz, en el vapor Antonio López, para regresar a Puerto Rico. En este caso no nos consta ninguna petición de licencia, aunque probablemente era a causa de su enfermedad ${ }^{137}$. Ignoramos también si en alguna de las tres ocasiones alcanzó visitar Cataluña; razones tenía, pues su hermano Francesc no falleció hasta 1880.

La última referencia de que disponemos sobre su actividad profesional es del 11 de abril de 1871, cuando Amadeo de Saboya lo declaró cesante ${ }^{138}$. Fidel Gatell falleció en 1872, víctima quizás de la disentería.

\section{c) Los descendientes}

En el momento de su fallecimiento, ninguno de los nueve hijos nacidos de los dos matrimonios de Fidel había alcanzado la mayoría de edad. El 31 de marzo de 1875 la Junta de Pensiones Civiles reconocía el derecho a percibir una pensión de orfandad de 2.000 pesetas anuales a Ana Rita, a sus hermanos Francisco Enrique, Pedro Tomás, José María, Federico Santiago, Rafael Ángel, Manuel Ricardo y María del Carmen y a la hermanastra María Elena Gatell López. Con el tiempo, María Elena y María del Carmen contrajeron matrimonio y la parte que disfrutaban el resto de los menores se incrementó. Finalmente, Ana Rita y Manuel Ricardo se repartirían la pensión a partes iguales, hasta que el 25 de enero de 1890, al producirse la boda de Ana Rita, quedó Manuel como único beneficiario. Cuando el 10 de junio de 1892 éste alcanzó la mayoría de edad, la pensión quedó en suspenso ${ }^{139}$.

El 24 de octubre de 1889 Ana Rita se había casado con Carlos Borch, pero a raíz de la defunción de su marido, en 1894, solicitó recuperar la pensión: entonces tendría unos 30 años. El 20 de febrero de 1897 la Junta de Clases Pasivas,

136. AHN. Ultramar. Legajo 1093, Exp. 24. Nombramiento de Fidel Gatell como Contador de la Aduana de Ponce, Gijón, 16 de agosto de 1858. Chronicling America: Historic American Newspapers. Lib. of Congress. Gazeta de Puerto-Rico. volume (None), Gaceta de Puerto Rico, núm. 66, 2 de junio de 1864. Escalafón general de los empleados del ramo de Hacienda de la Isla de Puerto Rico, en el artículo $6^{\circ}$ de la Real Orden de 26 de agosto de 1863.

137. AHN. Ultramar. Legajo 1093, Exp. 24. Nombramiento de Fidel Gatell como Oficial $1^{\circ}$ de la Contaduría Central de Hacienda, Madrid, 27 de noviembre de 1870.

138. AHN. Ultramar, legajo 1093, Exp. 24. Certificación del Comandante de Marina de Cádiz, 30 de noviembre de 1870 y Cesantía como oficial de contaduría.

139. AHN. Ultramar, legajo 6292, Exp. 18. Solicitud de pensión de orfandad de los hermanos Gatell García de Quevedo. 
desestimó su petición porque, según la legislación vigente, había caducado el derecho de volver a disfrutarla ${ }^{140}$.

De los hijos de Fidel Gatell y de Ana García de Quevedo, cinco -José María, Pedro Tomás, Federico, Rafael Ángel y Manuel Ricardo- fueron farmacéuticos, Francisco se estableció como comerciante. Rafael Ángel también era médico.

\section{Conclusiones}

La vocación marinera y comercial de Torredembarra durante el siglo XVIII resulta evidente, tanto por el volumen de intercambios que quedan reflejados en la contabilidad de su aduana como por los numerosos desplazamientos que protagonizaron sus naturales hacia el continente americano. Entre 1778 y 1833 , más de una tercera parte de los emigrantes originarios del Camp de Tarragona que se desplazaron a América, procedían de Torredembarra y su territorio anejo, Clarà.

En este contexto se mueve Fidel Gatell Moragas, un joven perteneciente a una próspera familia del Camp de Tarragona. Su padre era un hacendado de Torredembarra y su madre descendiente de los Moragas de Valls, de dilatada tradición mercantil.

Esta inclinación de sus paisanos a desplazarse hacia las colonias no pasó desapercibida a Fidel Gatell Moragas, quien, cuando consideró tener suficiente preparación y edad, no dudó en seguir sus pasos.

Probablemente, el hecho de ser el tercero y último de los hermanos -segundo de los varones- que le apartaba del derecho de primogenitura, por lo que si quería prosperar tenía que valerse por sí mismo, condicionó que la aventura americana entrara en sus planes, con la posibilidad añadida de hacer fortuna rápidamente. Estar emparentado con la adinerada familia Moragas tampoco debía satisfacerle, puesto que, a pesar de que sus abuelos poseían una sucursal de su compañía en Cuba, decidió que el destino de su viaje fuera Puerto Rico.

Su deseo, como confiesa en una de sus cartas, era regresar tarde o temprano a Cataluña. Sin embargo echó raíces en la isla caribeña y, aunque regresó tres veces -confirmado en una de ellas que fue para convalecer de la disentería que padecía-, no sabemos si llegó a visitar a su familia.

De los emigrantes americanos nos queda el recuerdo de los que hicieron fortuna: son los que regresaron y en sus localidades construyeron suntuosas mansiones, viviendo a la sombra de sus prósperos negocios. En el olvido permanecen aquellos que vieron frustradas sus esperanzas. Fidel Gatell comenzó su andadura trabajando en una casa de comercio, compaginando esta actividad

140. AHN. Ultramar, legajo 6292, Exp. 18. Solicitud de pensión de orfandad de los hermanos Gatell García de Quevedo. 
con la gestión de su propia finca en Añasco, aunque por lo que conocemos de su trayectoria no acabó triunfando en el mundo de los negocios.

En Añasco fue reconocido socialmente, primero como regidor y en 1845 como alcalde. A finales del año siguiente el conde de Mirasol le nombraba teniente a guerra y posteriormente sargento de las milicias urbanas. Después de asumir estas responsabilidades comenzaría su carrera de funcionario, primero como Vista de la aduana de Ponce, a continuación como Contador de la misma aduana, hasta finalizar en 1870 como Oficial primero de la Contaduría Central de Hacienda.

Desde su empleo como funcionario no podemos afirmar que hiciera fortuna, como pretendía en un principio. Incluso para poder hacer frente a posibles responsabilidades al finalizar su actividad profesional, precisó que alguien cercano le facilitara la fianza que le permitió acceder a la administración del Estado.

Su temprana desaparición -falleció con apenas 60 años-, unido a que contrajo matrimonio cuando ya había alcanzado una cierta madurez, contribuyó a que su numerosa descendencia -tuvo hasta nueve hijos- hubiera de solicitar una pensión de orfandad. A pesar de estas circunstancias, cinco de los varones llegaron a ser farmacéuticos y uno comerciante. Gracias a uno de sus descendientes, René Purcell Gatell -a quién tuve el placer de conocer-, sabemos que a lo largo del siglo XX algunos de sus familiares se diseminaron por Estados Unidos y países de América del Sur, mientras que otros siguen residiendo en Puerto Rico. 